\title{
STUDIES ON THE CIRCULATION IN MAN
}

\author{
XIII. THE BLOOD FLOW IN THE HANDS AND FEET IN CERTAIN DISEASES \\ OF THE NERVOUS SYSTEM * \\ G. N. STEWART, M.D. \\ CLEVELAND
}

The study of the blood flow in the hands and feet is of special interest in diseases of the nervous system, in which the extremities are so often involved. The skeletal reflexes are so frequently affected that it seemed of some consequence to explore also the vasomotor reflexes by the method described in previous papers. ${ }^{1}$ A preliminary account of some of the work was given in a Harvey Lecture. ${ }^{2}$ The material available of course allowed a more complete study of some conditions than of others. Also, in a first survey, those conditions were naturally selected in which changes in the blood flow or in the vascular reflexes seemed most likely to be detected, and if detected to be capable of being most clearly related to the symptoms and morbid anatomy of the diseased states. Such conditions as affected only one side (hemiplegia, unilateral peripheral neuritis) were obviously of interest not only in connection with the pathologic physiology of the circulation, but also as affording the opportunity of testing still further the technic of the method, since they permitted the direct comparison of a normal part with the corresponding diseased part.

For one or other of these reasons it happens that most of the material studied in this paper falls under one of three heads: (1) Peripheral neuritis (due to trauma, rheumatism, alcohol, etc.); a case or two in which the condition was probably neuralgia rather than neuritis is included in this group; (2) cerebral hemorrhage (or obstruction of cerebral vessels) with hemiplegia, and (3) tabes. Some other cases are also introduced mainly for the sake of comparison. These comprise cases of motor neuron disease, cerebral tumor, and gunshot wound of the brain. Some observations, chiefly on the vascular reflexes, were made on patients affected by certain poisons which act especially on the nervous system (alcohol, lead), but in whom at the time of observation no symptoms of actual anatomic lesions (peripheral neuritis) were present. A case of excessive tobacco smoking and a

\footnotetext{
* Submitted for publication March 25, 1915.

* From the H. K. Cushing Laboratory of Experimental Medicine, Western Reserve University.

1. Paper II of this series, Heart, 1911, iii, 76; Papers IX, X and XI, THE Archives Int. Med., 1913, xii, 678; Ibid., 1914, xiii, 1, 177.

2. Nov. 23, 1912.
} 
patient recovering from tetanus under treatment with antitoxin are also included because the vasomotor reflexes seemed to present points of interest. In one or two instances the blood-flow measurements were applied to the detection of malingering with, it is thought, helpful or at least suggestive results.

\section{PERIPHERAL NEURITIS}

In three cases of unilateral brachial neuritis, not of long standing, in which no decided atrophy of the hand had as yet occurred, although the strength of the grip was markedly diminished, the blood flow in the affected hand was conspicuously greater than in the contralateral normal hand. In two of these cases the lesion was on the right side and as has been mentioned in previous papers, normal right-handed persons usually show a slight preponderance in blood flow per 100 c.c. of hand volume on the right side. In the cases referred to, however, the difference was much greater, and one of the cases in which the lesion was on the left side presented an equally large excess in the left hand.

Thus in O. A. H., a man with right brachial neuritis probably of tratumatic origin, and not at the time of observation associated with any wasting in the right hand, the flow in the right hand was 8.79 grams and in the left hand 6.99 grams per 100 c.c. of hand per minute, with room temperature $24 \mathrm{C}$. The ratio of the flows in the two hands $(1: 1.26)$ shows a very decided preponderance of flow in the affected hand.

O. A. H., a house carpenter aged 60 , was admitted to the dispensary January 25, suffering from right brachial neuritis. Seven years ago he fell from a building on his right shoulder and has always had some pain in shoulder since. For three months he had severe pain and weakness in his shoulder. Pain is felt on pressure over the circumflex and over the median nerve above the elbow, and tenderness over the brachial plexus in neck and axilla. The grip of the right hand is much less strong than that of the left. Slight numbness is the only sensory disturbance. All movements of the right arm are weak, but there is no wasting of the hand. February 24: The systolic blood pressure is 130 No impairment of tactile sensation exists and warmth and cold sensibility is good. Pain sensation is diminished below the elbow. On April 26 his arm was better. The blood flow in the hands was examined January 12, before admission. Hands in bath at $3 \mathrm{p} . \mathrm{m}$.; in calorimeters at $3: 10 \mathrm{p}$. m.; removed from calorimeters at $3: 26$. 3,050 c.c. of water were in each calorimeter. Room temperature $24.1 \mathrm{C}$.

In Casimir M., a man aged 27, with left brachial neuritis, the blood flow in the right hand was 5.63 grams, and in the left hand 7.40 grams per 100 c.c. per minute, with an average room temperature of $21.9 \mathrm{C}$. The ratios of the flows in the two hands is $1: 1.31$, indicating a great excess in favor of the left hand. The case may fairly be considered an "early" one. Although there was some wasting of the muscles of the left upper arm, and some weakening of the grasp of the left hand, 
little if any wasting of the hand as revealed by the volume measurement could be detected.

Table 1.-Calorimetric Measurements in Case of O. A. $\mathrm{H}$.

\begin{tabular}{l|l|l}
\hline \hline Time & Right & Left \\
\hline $3: 00$ & 29.98 & 29.87 \\
$3: 12$ & 30.00 & 29.89 \\
$3: 13$ & 30.03 & 29.91 \\
$3: 14$ & 30.09 & 29.94 \\
$3: 15$ & 30.13 & 29.97 \\
$3: 16$ & 30.20 & 30.01 \\
$3: 17$ & 30.23 & 30.02 \\
$3: 19$ & 30.32 & 30.10 \\
$3: 20$ & 30.38 & 30.13 \\
\hline
\end{tabular}

\begin{tabular}{l|c|c}
\hline Time & Right & Left \\
\cline { 1 - 1 } $3: 21$ & 30.43 & 30.18 \\
$3: 22$ & 30.50 & 30.25 \\
$3: 23$ & 30.57 & 30.30 \\
$3: 24$ & 30.63 & 30.36 \\
$3: 25$ & 30.71 & 30.41 \\
$3: 26$ & 30.78 & 30.48 \\
$3: 35$ & 30.68 & 30.40 \\
$3: 51$ & 30.52 & 30.26 \\
& & \\
\hline
\end{tabular}

Cooling of calorimeters in twenty-five minutes, R., 0.26 C., L., $0.22 \mathrm{C}$. Volume of right hand in calorimeter, 445 c.c. of left 425 c.c. Pulse $80 . *$ Mouth temperature $37.1 \mathrm{C}$. Room temperature 23.9. He is right handed.

* Except when otherwise mentioned the pulse rate was always taken in a sitting position.

$\dagger$ It is to be assumed that a patient is right handed unless the contrary is stated.

Casimir M. was admitted to the dispensary, January 4, with left brachial neuritis. He had noticed pain in the left elbow for three months, mostly when at work (as a sewing machine operator). He had had no injury. No local signs were seen at elbow. There was no history of venereal infection. Considerable thickening of the radial artery existed. On January 31 the left arm was still weak and he could not use it properly at work, while there was distinct atrophy of some of its muscles. The circumference of the left upper arm was $24.5 \mathrm{~cm}$., that of right upper arm $26.5 \mathrm{~cm}$., of left forearm $25 \mathrm{~cm}$., and of right $26 \mathrm{~cm}$. Pain on pressure was felt over some of the cervical nerves on the left side, but no pain on pressure over the arm. The grasp of the left hand was weaker than that of the right. On February 17 he felt much better. The blood flow in the hands was examined January 31.

The hands were put into the bath at $3: 38 \mathrm{r} / 2 \mathrm{p} . \mathrm{m}$., into the calorimeters at $3: 51$, taken out of calorimeters at $4: 08$. 3,050 c.c. of water were in each calorimeter. Pulse 68. Mouth temperature $36.6 \mathrm{C}$.

table 2.-Calorimetric Measurements in Case of Casimir M.

\begin{tabular}{ll|l|c}
\hline Time & Right & Left & Room \\
\hline $3: 50$ & 29.40 & 29.36 & \\
$3: 52$ & 29.39 & 29.35 & 21.7 \\
$3: 54$ & 29.42 & 29.41 & \\
$3: 55$ & 29.44 & 29.42 & \\
$3: 56$ & 29.45 & 29.43 & \\
$3: 57$ & 29.47 & 29.43 & 22.1 \\
$3: 58$ & 29.49 & 29.48 & \\
$3: 59$ & 29.52 & 29.51 & \\
$4: 00$ & 29.55 & 29.53 & \\
\hline
\end{tabular}

\begin{tabular}{l|c|c|c}
\hline Time & Right & Left & Room \\
\hline $4: 01$ & 29.58 & 29.58 & \\
$4: 02$ & 29.61 & 29.62 & \\
$4: 03$ & 29.64 & 29.65 & \\
$4: 04$ & 29.68 & 29.71 & \\
$4: 05$ & 29.71 & 29.75 & \\
$4: 06$ & 29.76 & 29.81 & \\
$4: 07$ & 29.78 & 29.83 & 21.9 \\
$4: 08$ & 29.80 & 29.86 & \\
$4: 27$ & 29.56 & 29.63 & \\
\hline
\end{tabular}

Cooling of calorimeters in nineteen minutes, R., 0.24 C., L., 0.23 C. Volume of right hand 400 c.c., of left hand 370 c.c.

In John S., a man with right brachial neuritis and distinct weakening although no definite wasting of the right hand, the flows were 10.29 grams and 7.66 grams per 100 c.c. per minute in the right and 
left hands respectively, with room temperature $22.3 \mathrm{C}$. The ratio of the flows $(1: 1.34)$ denotes a great preponderance of flow in the hand affected by the lesion. On immersion of the left hand in cold water the flow in the right sank to 5.18 grams per 100 c.c. per minute for the first four minutes and then rose to 8.16 grams per 100 c.c. per minute for the remaining five minutes of the period of immersion. On immersing the left hand in warm water the flow in the right hand mounted to 10.16 grams, which was scarcely equal to the initial flow. This indicates that the flow in the right hand at the beginning of the observation was probably already associated with a considerable vasodilatation on which it was easy to impose a decided reflex vasoconstriction but not an additional vasodilatation.

John S., a bricklayer aged 45, was admitted to the dispensary on February 27 with neuritis in the right arm. He had had pain in right elbow for four weeks, unaccompanied by heat or swelling, and the arm had lost strength. The grip of the right hand was much weaker than that of the left. Tenderness was felt over the external condyle, and very slight tenderness over the right brachial plexus. He attributed the condition to cold. March 6, his condition was the same. The blood flow in the hands was examined February 27.

The hands were put into the bath at 2:50 p. m., into the calorimeters * at 3 , removed from calorimeters at $3: 37$. At $3: 15$ the left hand was immersed in water at $9 \mathrm{C}$, and at $3: 24$ in water at $43 \mathrm{C}$. At $3: 31$ the left hand was dried and wrapped up. Pulse 74 . Mouth temperature $36.74 \mathrm{C}$.

table 3.-Calorimetric Measurements in Case of John S.

\begin{tabular}{l|l|l|l}
\hline Time & Right & Left & Room \\
\cline { 1 - 2 } $2: 591 / 2$ & 29.61 & 29.50 & \\
$3: 02$ & 29.69 & 29.55 & 23.3 \\
$3: 03$ & 29.72 & 29.59 & \\
$3: 04$ & 29.78 & 29.63 & \\
$3: 05$ & 29.84 & 29.67 & \\
$3: 06$ & 29.90 & 29.71 & \\
$3: 07$ & 29.96 & 29.75 & \\
$3: 08$ & 30.02 & 29.83 & 23.4 \\
$3: 03$ & 30.09 & 29.88 & \\
$3: 10$ & 30.16 & 29.92 & \\
$3: 11$ & 30.21 & 29.96 & \\
$3: 12$ & 30.28 & 30.03 & \\
$3: 13$ & 30.33 & 30.06 & \\
$3: 14$ & 30.39 & 30.11 & 22.8 \\
$3: 15$ & 30.45 & 30.15 & \\
$3: 16$ & 30.48 & & \\
$3: 17$ & 30.50 & $\ldots .$. & 23.3 \\
$3: 18$ & 30.52 & & \\
$3: 19$ & 30.53 & & \\
& & & \\
\hline
\end{tabular}

\begin{tabular}{|c|c|c|c|}
\hline Time & Right & Left & Room \\
\hline $\begin{array}{l}3: 20 \\
3: 21 \\
3: 22 \\
3: 23 \\
3: 24 \\
3: 25 \\
3: 26 \\
3: 27 \\
3: 28 \\
3: 29 \\
3: 30 \\
3: 31 \\
3: 32 \\
3: 33 \\
3: 34 \\
3: 35 \\
3: 36 \\
3: 37 \\
3: 43\end{array}$ & $\begin{array}{l}30.57 \\
30.61 \\
30.66 \\
30.69 \\
30.73 \\
30.77 \\
30.81 \\
30.87 \\
30.91 \\
30.97 \\
31.02 \\
31.08 \\
31.11 \\
31.14 \\
31.19 \\
31.23 \\
31.27 \\
31.30 \\
31.22\end{array}$ & $\begin{array}{c}\cdots \cdots \\
29.91\end{array}$ & 23.3 \\
\hline
\end{tabular}

Volume of right hand 412 c.c., of left hand 402 c.c. Cooling of calorimeters, R., $0.08 \mathrm{C}$. in six minutes, L., $0.24 \mathrm{C}$. in twenty-eight minutes.

The most natural explanation of the preponderance in the flow on the side of the lesion is that the vasoconstrictor fibers are involved in the neuritis, with a resultant diminution of the vasomotor tone of the hand. It is difficult to see how a neuritis due to trauma or to pressure

* As always, unless otherwise stated, the quantity of water in each hand calorimeter was 3,015 c.c. 
could fail to affect these fibers. Nor is there any evidence that they escape completely in other forms of peripheral neuritis although, until it is eliminated by proof to the contrary, the possibility must be granted that a particular poison may spare the efferent vasomotor fibers in the peripheral nerves which it attacks. In a peripheral neuritis involving the vasocontrictors these need not of course be totally incapable of conduction any more than the motor fibers of the part. In the case of John S., for example, it is evident they were not completely paralyzed, since a good reflex vasoconstriction was obtained when the contralateral hand was put into cold water. There is some indication, however, that such a reflex, even when of as great an initial intensity as normal, may be more fleeting than under normal conditions, perhaps because the partially degenerated fibers or their endings are sooner fatigued.

In a fourth case, that of Kaspar J., a man suffering from "early" unilateral brachial neuritis apparently of rheumatic origin, a similar disproportion between the flows in the two hands was noticed, the preponderance being, as before, in favor of the affected hand. Later on, however, in this case practical equality in the flows in the two hands was observed, either because the improvement in the condition had progressed so far at the second examination that the vasomotor tone of the affected hand had again become normal, or possibly because of the action of the salicylates with which he was being treated. At the first examination the flow in the hand on the side of the neuritis (the right) was 4.80 grams per 100 c.c. per minute (allowing for the swelling of the hand) and in the left 3.58 grams, the ratio being $1: 1.34$, with room temperature $24.2 \mathrm{C}$. These flows are subnormal, which may of course be due to the man's general condition, recovering as he was from an acute illness (rheumatic fever). The heart was probably to some extent handicapped. Also arteriosclerosis was present, which is always associated with a subnormal hand flow. ${ }^{3}$

At the second examination with a somewhat higher room temperature $(25.3 \mathrm{C}$.) the flow was practically the same in the left hand $(3.72$ grams) but in the right hand it was reduced almost to equality with that in the left ( 3.76 grams per 100 c.c. per minute). The fact that the flow in the left hand remained so low in spite of the relatively high room temperature seems to indicate a great tendency to vasoconstriction. If this were the case we should expect that the preponderance of flow previously observed in the right hand, which by hypothesis was due to diminution, though not to paralysis, of vasoconstrictor tone, should tend to disappear. The slight tendency to vasodilatation is indicated clearly by the tests of the vasomotor reflexes. During immer-

3. Paper XI of this series, The Archives Int. Med., 1914, xiii, 177. 
sion of the left hand in warm water the flow in the right sank to 2.68 grams per 100 c.c. per minute for the first four minutes of immersion and only reached 4.12 grams per 100 c.c. per minute for the remaining seven minutes. For the first three minutes of immersion of the left hand in cold water the flow in the right was 2.74 grams and for the remaining six minutes 3.75 grams per 100 c.c. per minute. The marked slowing of the pulse rate ( 57 per minute as compared with 92 at the previous examination), in spite of the higher room temperature and the unchanged body temperature, may be associated with the tendency to peripheral vasoconstriction.

Kaspar J., a laborer, aged 50, was admitted to Lakeside Hospital, April 12, with rheumatic fever. Two weeks before, he began to have severe pain in the left ankle and knee, later in the right knee. Five days before admission the right elbow, wrist, and later the shoulder began to trouble him. The heart sounds were clear; the pulse regular in rate, but irregular in amplitude. The vessel wall was palpable. On April 20 the legs were well, but the right upper arm was still sensitive and much atrophied. On April 30 there was very little pain, but movement of the right arm was much impaired; analgesia existed over the entire right arm. The blood flow in the hands was examined May 5 and again May 8. The grip of the right hand was still weak; pain was felt over the right brachial plexus. Convalescence was uninterrupted and he was discharged May 12.

The hands were put into the bath at $2: 361 / 2 \mathrm{p}$. m., into the calorimeters at $2: 46 \mathrm{I} / 2$. At $2: 56 \mathrm{r} / 2$ the left hand was put into water at $43 \mathrm{C}$. At $3: 04$ the left hand was put into water at $9.5 \mathrm{C}$. He felt the cold water painful. At 3:13 the right hand was removed from the calorimeter. Pulse 92. Mouth temperature 36.7 .

TABLE 4.-First Blood Flow Examination of Kasper J.

\begin{tabular}{l|l|l|l}
\hline \hline Time & Right & Left & Room \\
\hline $2: 45$ & 29.65 & 29.56 & \\
$2: 48$ & 29.67 & 29.57 & \\
$2: 49$ & 29.69 & 39.60 & \\
$2: 50$ & 29.71 & 29.62 & \\
$2: 51$ & 29.75 & 29.63 & \\
$2: 52$ & 29.78 & 29.64 & \\
$2: 53$ & 29.80 & 29.67 & \\
$2: 54$ & 29.84 & 29.70 & \\
$2: 55$ & 29.88 & 29.72 & 24.2 \\
$2: 56$ & 29.90 & 29.74 & \\
$2: 57$ & 29.93 & 29.76 & \\
$2: 58$ & 29.965 & & \\
$2: 59$ & 29.95 & $\ldots \ldots$ & 24.2 \\
$3: 00$ & 30.03 & & \\
$3: 0 ?$ & 30.07 & & \\
& & & \\
\hline
\end{tabular}

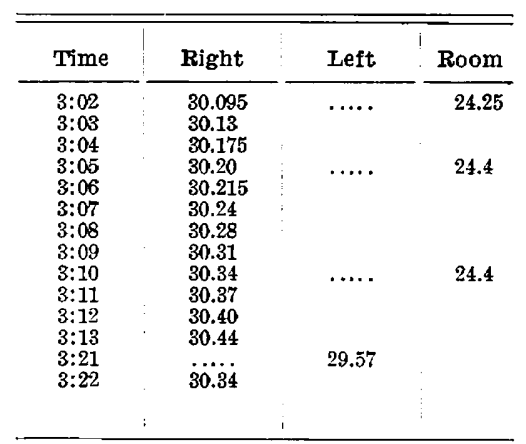

Volume of right hand 511 c.c., of left 457 c.c. The right hand is still somewhat swollen and noticeably larger than the left. Cooling of calorimeters, R., $0.10 \mathrm{C}$. in nine minutes, L., $0.19 \mathrm{C}$. in twenty-four minutes.

The particulars of the second examination of Kasper $J$. are given in the general table.

In a fifth case (John McH.), although symptoms described by the patient suggested a right brachial neuritis, the suspicion of malingering could not be excluded. The flow in the right hand was 4.30 grams 
and in the left 3.91 grams per 100 c.c. per minute with room temperature at $23.3 \mathrm{C}$. The ratio of the flow of the two hands is $1: 1.1$. On the following day another examination was made and the flows cane out 5.46 grams and 4.74 grams for the right and left hands respectively with the same room temperature, a ratio of $1: 1.15$. Immersion of the left hand in warm water caused a marked vasoconstriction in the right hand for the first six minutes, reducing the flow to 3.23 grams per 100 c.c. per minute. This was succeeded by a moderate vasodilatation (for the remaining seven minutes of the period of immersion of the left hand) the flow in the right hand increasing to 6.11 grams.

John McH., a laborer, aged 58, was admitted to the City Hospital, June 4 , apparently suffering from right brachial neuritis. He complained of stinging and numbness of right forearm and hand, especially the middle finger. He had been addicted to alcohol and had several attacks of delirium tremens. There was pain on pressure over the right shoulder, at the inner side and front of the head of the humerus. He could raise his right arm slowly and apparently with some pain to the horizontal position but not higher. His hands felt cold. He said he was cold all over. He stated that he sometimes had sudden swelling of the back of the right hand, which disappeared in a few minutes. He har. no trouble in walking but said he was "very irritable and twitched a great deal." There seemed to be a considerable mental factor in the case and a possibility of malingering. The pain and tingling did not inconvenience him, but he feared they might be premonitory of a "stroke." Blood flow in hands was examined on June 5 and again on June 6 . Particulars of the first bloodflow examination are given in the general table.

Table 5.-Calorimetric Measurements in Second Examination of JоHN MCH.

\begin{tabular}{|c|c|c|c|}
\hline Time & Right & Left & Room \\
\hline $\begin{array}{l}2: 40 \\
2: 42 \\
2: 43 \\
2: 44 \\
2: 45 \\
2: 46 \\
2: 47 \\
2: 48 \\
2: 49 \\
2: 50 \\
2: 51 \\
2: 52 \\
2: 53 \\
2: 54 \\
2: 55 \\
2: 56 \\
2: 57 \\
2: 58 * \\
2: 59\end{array}$ & $\begin{array}{l}31.40 \\
31.39 \\
31.40 \\
31.41 \\
31.425 \\
31.46 \\
31.49 \\
31.52 \\
31.54 \\
31.575 \\
31.59 \\
31.60 \\
31.625 \\
31.66 \\
31.68 \\
31.71 \\
31.75 \\
31.78 \\
31.795\end{array}$ & $\begin{array}{l}31.31 \\
31.31 \\
31.32 \\
31.33 \\
31.35 \\
31.875 \\
31.41 \\
31.425 \\
31.44 \\
31.46 \\
31.48 \\
31.49 \\
31.52 \\
31.54 \\
31.55 \\
31.58 \\
31.625 \\
31.635 \\
31.65\end{array}$ & $\begin{array}{l}23.1 \\
23.2\end{array}$ \\
\hline
\end{tabular}

\begin{tabular}{l|l|l|l}
\hline \hline Time & Right & Left & Room \\
\hline $3: 00$ & 31.80 & 31.66 & \\
$3: 01$ & 31.835 & 31.695 & \\
$3: 02$ & 31.85 & 31.71 & 23.15 \\
$3: 03$ & 31.88 & 31.72 & \\
$3: 04$ & 31.88 & $\ldots \ldots$ & 22.9 \\
$3: 05$ & 31.89 & & \\
$3: 06$ & 31.90 & & \\
$3: 07$ & 31.91 & & \\
$3: 08$ & 31.925 & $\ldots \ldots$ & 22.9 \\
$3: 09$ & 31.935 & & \\
$3: 10$ & 31.965 & & \\
$3: 11$ & 31.99 & $\ldots \ldots$ & 23.05 \\
$3: 12$ & 32.02 & & \\
$3: 13$ & 32.045 & & \\
$3: 14$ & 32.075 & & \\
$3: 15$ & 32.09 & $\ldots \ldots$ & 23.0 \\
$3: 16$ & 32.12 & & \\
$3: 39$ & 31.82 & 31.29 & \\
& & & \\
\hline & & &
\end{tabular}

Cooling of calorimeters, R., $0.30 \mathrm{C}$. in twenty-three minutes, L., $0.43 \mathrm{C}$. in thirty-six minutes. Rectal temperature $37.5 \mathrm{C}$. Volume of right hand 512 c.c., of left 491 c.c. Water equivalent of calorimeters with contents, R., 3,504, L., 3,488. Blood pressure left arm, systolic 116, 93 (sound gone). Right arm, $115,93$.

* Here he heard warm water ordered and became anxious. 
At the second examination the patient says the pain in the right shoulder is rather worse than yesterday. The hands were placed in bath at 2:32 p. m., in the calorimeters at $2: 41 \frac{1}{2}$, taken out of calorimeters at $3: 16$. Pulse 88 . At 3:03 left hand was put into water at $43 \mathrm{C}$.

While it would of course be absurd to claim that such observations would of themselves be sufficient to justify a diagnosis of malingering in this case the slight difference in the flows in the two hands, scarcely exceeding if at all that often observed in normal persons, suggested that if the symptoms described were genuine they were due rather to a functional than to a structural lesion-to a brachial neuraigia rather than to an "early" brachial neuritis. In the period during which the patient was still under observation the condition did not develop further and he was discharged "improved" a very few days after the last examination. There is little doubt that in cases in which certain neurologic conditions are simulated a measurement of the blood flow might sometimes help to clear up the diagnosis. In long-standing paralyses whether due to a peripheral or to a central lesion there is a decided diminution in the blood flow of the affected hand (or foot) as compared with the normal part.

Thus, in a case of long-standing brachial neuritis of the right side associated with cervical rib (Mrs. M. C.) the flow was much smaller in the affected than in the normal hand (3.98 grams per 100 c.c. per minute in the right, and 5.70 grams in the left hand) the ratio being $1: 1.43$, with room temperature $23.5 \mathrm{C}$.). This agreed with the statement of the patient that the right hand was always colder than the left. There was slight wasting of the right hand, only clearly revealed by measurement of the volume, but the hand was little used. The atrophy chiefly affected the proximal segments of the limb. Here it may be supposed that the nerve lesion has led to anatomic changes in the blood vessels causing a narrowing of their lumen. ${ }^{4}$

Mrs. M. C., aged 38, was admitted to the dispensary in April, 1910. She states that in her fourteenth year she worked very hard in a hayfield on a hot day, had sunstroke and fell unconscious. When she recovered consciousness, right arm and shoulder were aching and there was some loss of power there. This has gone on gradually increasing. Continuous pains have been in the right shoulder for the past three weeks. There is exostosis of the scapula (curved scapula) and a marked prominence in right supraclavicular region extending upward and forward for two inches and pressing on the brachial plexus. Cervical ribs were shown by Roentgen ray. Extreme tenderness was felt on pressure in supraclavicular region. Atrophy and weakness were noted of the serratus magnus, infraspinatus, supraspinatus, and latissimus dorsi. The deltoid and other muscles of the arm and forearm show weakness and slight atrophy. There was no apparent wasting of the right forearm or hand, although she does not now use them much. The grip of the right hand was fairly strong, although weaker than the left. She was right handed. There

4. Todd: Jour. Nerv. and Ment. Dis., 1913, xl, 439. 
was a marked diminution of sensation to pricking and to contact with camel's hair brush over right shoulder. Over arm and forearm sensation is normal. Blood flow in hands was examined Feb. 14, 1911.

Hands in bath at 2:03 p. m., were placed in calorimeters at $3: 14$, and taken out of calorimeters at $3: 29$. Pulse 88 . Mouth temperature $37.4 \mathrm{C}$. Room temperature $23.8 \mathrm{C}$.

Table 6.-Calorimetric Measurements in Case of Mrs. M. C.

\begin{tabular}{cccc}
\hline Time & Right & Left \\
\hline $3: 13$ & 30.29 & & 30.27 \\
$3: 16$ & 30.27 & & 30.27 \\
$3: 17$ & 30.29 & & 30.31 \\
$3: 18$ & 30.30 & & 30.33 \\
$3: 19$ & 30.31 & & 30.34 \\
$3: 20$ & 30.33 & 30.38 \\
$3: 21$ & 30.35 & 30.41 \\
$3: 22$ & 30.36 & 30.43 \\
\hline
\end{tabular}

\begin{tabular}{|c|c|c|c|c|}
\hline Time & & Right & : & Left \\
\hline $\begin{array}{l}3: 23 \\
3: 24 \\
3: 25 \\
3: 26 \\
3: 27 \\
3: 28 \\
3: 29 \\
3: 54\end{array}$ & $!$ & $\begin{array}{l}30.38 \\
30.39 \\
30.40 \\
30.41 \\
30.42 \\
30.43 \\
30.44 \\
30.21\end{array}$ & 1 & $\begin{array}{l}30.46 \\
30.48 \\
30.50 \\
30.51 \\
30.52 \\
30.55 \\
30.57 \\
30.34\end{array}$ \\
\hline
\end{tabular}

Cooling of the calorimeters in twenty-five minutes, $0.23 \mathrm{C}$. Volume of right hand 295 c.c., of left hand 301 c.c.

The possibility of distinguishing a neuralgia from an "early" neuritis by measurement of the blood flow seems to be indicated by such cases as that of Max B., a carpenter, aged 24, in whom the diagnosis of occupational neuralgia (possibly with slight neuritis) was made.

The blood flow came out 13.89 grams per 100 c.c. per minute for the right (the affected) hand and 13.38 grams for the left, with room temperature $24.5 \mathrm{C}$. (ratio of flows in the two hands $1: 1.04$ ). These flows are of a normal order of magnitude for the age and general condition of the patient and the room temperature. The slight preponderance of flow in the right hand is no more than that usually observed in normal right-handed persons. If the condition were a typical "early" neuritis a much greater excess of flow in the affected hand would be expected, owing to paralysis of vasoconstrictors. The vasoconstrictor reflex in the right hand when the left was immersed in cold water was well marked, the flow falling to 7.25 grams for the first three minutes of immersion, but rising again during the remaining six minutes to 10.83 grams per 100 c.c. per minute. Immersion of the left hand in warm water caused a moderate increase in flow in the right (to 12.53 grams per 100 c.c. per minute for the whole period of immersion of seven minutes). The initial value was not reached. The vasomotor reflex to warmth in this experiment differed from that in normal cases and also from that in the cases of undoubted neuritis in this respect, that there was no distinct initial diminution of flow in the right hand when the left was put into the warm water, or a very slight and transient one. There is not enough material, however, to show whether this has any general significance. The protocol of the case has already been published. ${ }^{5}$

5. Cleveland Med. Jour., 1911, x, 398. 
One case diagnosed as sciatica of the left leg was examined.

Frank S., a man aged 64, a laborer in a stable, had to sleep about the stable, often on the wet floor. For six weeks previous to admission the leg had been growing rapidly worse. Now he can hardly bear his weight on it. The trouble is worse at night. Both knee-jerks are exaggerated, especially the left. The Achilles jerk is evident on the left side. Some tenderness is present along the nerve trunks of the left leg, which feels cold at times.

At the first examination of the blood flow-three days after admission when the condition was still acute--the flow in the feet was found exceedingly small both absolutely and in proportion to the hand flow, namely, 0.22 gram per 100 c.c. per minute for the right foot, and 0.47 gram for the left, with room temperature $21 \mathrm{C}$. Immersion of the right foot in warm water caused no increase in the flow in the left foot, which for ten minutes during immersion of the right foot continued at the rate of 0.43 gram per 100 c.c. per minute. The flow in the right hand was 4.20 grams, in the left 4.39 grams, with room temperature $22.1 \mathrm{C}$. The ratio of the combined foot flows to the combined hand flows was $1: 12.4$, indicating a marked tendency to vasoconstriction in the feet, possibly due in part to the pain. The fact that in spite of this tendency to vasoconstriction the flow in the left foot is double that in the right would seem to indicate a condition of the nerves of the left leg constituting a partial block for vasoconstrictor impulses. If a condition of neuritis of the large nerve trunks of the leg is present this would agree with the results on cases of brachial neuritis. Twenty-two days later, when the pain in the thigh had disappeared, the flow in the left foot was found somewhat inferior to that in the right, which agreed with the fact that for three or four days previous to the examination he had felt the left foot cold, although it was covered with sweat.

A number of cases of alcoholic neuritis came under observation. A detailed account of the results in one will suffice. A second case is considered in another connection in Paper XII, published in Journal of Experimental Medicine, xxii, 1915, No. 1.

Charles de M., a pianist, aged 29, height 6 feet, 1 inch, weight 170 pounds, was admitted to the City Hospital, July 9 , with diagnosis of chronic alcoholism with neuritis. He has been drinking since boyhood and drinks a quart of whisky daily. There is no noticeable anemia. The heart and lungs are normal. The liver is palpabie. Knee-jerk and tendo Achillis reflex are markedly exaggerated. A musculo-spiral paralysis of the left forearm and wrist with well-marked wrist drop is present. There is tenderness but no atrophy. The left hand is weaker than right; the left foot is also worse than the right. Two months ago there was marked toe-drop in the left foot. He could stand on the right foot alone but not on the left. The toe-drop is not now so bad. A general tremor exists. The maximum temperature on July 11 was $100.6 \mathrm{~F}$. After this it was never above $99.6 \mathrm{~F}$. with a minimum of $97.8 \mathrm{~F}$. The patient sweats freely. He was discharged improved, July 29. The blood flow in the hands 
was examined on July 10 and in the feet and hands on July 16. He was unable to walk into the room.

First examination, July 10: Hands in bath at $1: 58 \mathrm{r} / 2 \mathrm{p} . \mathrm{m}$., in calorimeters at $2: 08 \mathrm{r} / 2$. At $2: 25$ the right hand was put into water at $8.1 \mathrm{C}$., and at $2: 35$ into water at $43.1 \mathrm{C}$. He complained much of the cold water. At 2:44 the right hand was taken from the calorimeter. Pulse 68. The day was very warm.

Table 7.-Calorimetric Measurements in Case of Charles de $M$.

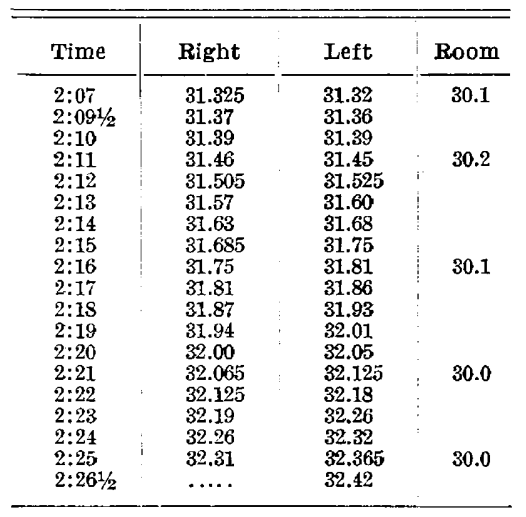

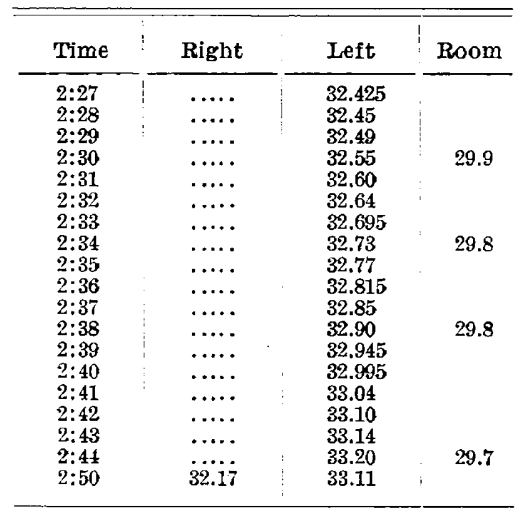

Cooling of calorimeters, R., $0.14 \mathrm{C}$. in thirty-four minutes, L., $0.09 \mathrm{C}$. in fifteen minutes. Volume of right hand 488 c.c., of left hand 479 c.c. Rectal temperature 37.5 C. Water equivalent of calorimeters with contents, R., 3,485, L., 3,478. Blood pressure left arm, systolic 118 (palpation), 121 (stethoscope), 74 (sound gone).

Second examination, July 16: The patient's left hand is to-day in a splint on account of wrist-drop. It feels stiff and swollen, probably from the pressure of the splint. He walked into the room without help and feels much better. Hands in bath at 3:07 p. m., were in calorimeters at 3:17, and out of calorimeters at $3: 29$. Pulse 84 . The weather is much colder than at the last examination.

Table 8.-Calorimetric Measurements in Second Examination of Charles de M.

\begin{tabular}{c|l|l|l}
\hline \hline Time & Right & Left & Room \\
\cline { 1 - 2 } $3: 15$ & 31.40 & 31.39 & 24.9 \\
$3: 18$ & 31.425 & 31.405 & 25.2 \\
$3: 19$ & 31.495 & 31.465 & \\
$3: 20$ & 31.56 & 31.51 & 25.15 \\
$3: 22$ & 31.66 & 31.60 & \\
$3: 23$ & 31.72 & 31.66 & \\
$3: 24$ & 31.79 & 31.71 & \\
\hline
\end{tabular}

\begin{tabular}{l|l|l|l} 
Time & Right & Left & Room \\
\hline $3: 25$ & R1.83 & 31.77 & \\
$3: 26$ & 31.90 & 31.805 & 25.1 \\
$3: 27$ & 31.95 & 31.855 & \\
$3: 28$ & 31.99 & 31.89 & \\
$3: 29$ & $\mathbf{3 1 . 0 3 5}$ & 31.935 & \\
$3: 35$ & 31.96 & 31.86 & \\
& & & \\
\hline
\end{tabular}

Cooling of calurimeters in six minutes, R., 0.075 C., L., $0.075 \mathrm{C}$. Volume of right hand 479 c.c., of left hand 494 c.c. Water equivalent of calorimeters with contents, R., 3,478, L., 3,490. Rectal temperature 37.7 C.

At the first examination in Charles de M. the flow in the right hand was 9.96 grams per 100 c.c. per minute, in the left (the weaker of the two hands) 10.76 grams, with the very high room temperature $30.1 \mathrm{C}$. The ratio between the flows in the two hands was $1: 1.08$. These flows 
are subnormal for his age at this room temperature. Immersion of the right hand in cold water caused a good reflex vasoconstriction, the flow in the left dropping to 5.84 grams per 100 c.c. per minute for the first three minutes, to rise again to 9.45 grams per 100 c.c. per minute for the next seven minutes of the immersion. Immersion of the right hand in warm water caused only a very moderate increase above the initial flow in the left hand (to 11.27 grams).

At the second examination, six days later, the flow was 9.92 grams for the right hand and 8.95 grams for the left with room temperature $25.1 \mathrm{C}$. These flows are fairly normal for the room temperature, and the patient's condition was much better than at the previous examination. His pulse rate was 84 instead of 68 . The deficiency in the flow in the left hand is probably to be attributed to obstruction caused by a splint. But in no patient with alcoholic neuritis examined has the same marked difference between the two hands (or feet) been observed as in the cases of brachial neuritis already described. Two points have to be considered in this relation-first, in alcoholic neuritis the action of the poison is necessarily bilateral, although the neuritis may at a particular time have progressed farther on the one side than on the other. Secondly, if, as appears often to be the case, it is the small muscular branches which are specially affected in alcoholic neuritis, a very marked increase in the blood flow of the hand most affected by the neuritis could scarcely be expected, since the hand flow is above all a cutaneous blood flow.

The flow in the feet at the second examination of Charles de M. came out 0.90 gram per 100 c.c. per minute for the right foot and 1.20 grams for the left. These flows are not only absolutely small, but small in proportion to the hand flows. The preponderance is on the side (left) on which the foot-drop is worse, but in dealing with such small flows, particularly in the case of the feet in which vasoconstriction caused by the necessary manipulations connected with the measurement is not easily avoided in patients specially susceptible to this condition, too much stress must not be laid on small differences. The next case, although the patient was much addicted to alcohol, probably represents a neuritis due to pressure.

Frank D., aged 39, height 5 feet, 11 inches, a school teacher in Germany, since then a casual laborer, was admitted to the City Hospital, July 22, with wrist-drop of left hand. Pronation and supination are perfect. He can palmarflex left hand to some extent but cannot dorsiflex it. He has long been a heavy drinker and has had delirium tremens. Has been sleeping outside. On the morning of July 21 he first noticed that he could not move his left hand. For all he knows he may have been lying on it. He never had anything of the kind before. Some numbness is present on the dorsum of the left hand, especially on the radial side, although pin pricks and contact of the blunt point are felt everywhere. Wrist-jerk is absent on the left side, but is well marked on the right. Knee-jerk is present on both sides. The heart and lungs are normal. 
There is no noticeable anemia. He was discharged improved July 27. The blood flow in the hands was examined July 23.

The hands in bath at 1:54 p. m., were in calorimeters at 2:06. Left hand out of calorimeter at $2: 47$. The right hand was put into cold water $(8 \mathrm{C}$.) at $2: 23 \mathrm{p}$. m. Pulse 76 . At 2:34 right hand was put into water at $43 \mathrm{C}$.

table 9.-Calorimetric Measurements in Case of Frank D.

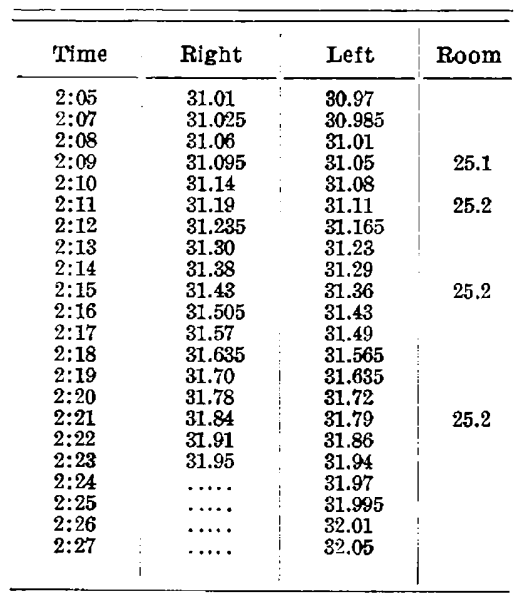

\begin{tabular}{|c|c|c|c|}
\hline Time & Right & Left & Room \\
\hline $\begin{array}{l}2: 28 \\
2: 29\end{array}$ & $\ldots .$. & .32 .075 & 25.1 \\
\hline $2: 30$ & $\cdots \cdot$ & $\begin{array}{l}32.13 \\
32.17\end{array}$ & 25.05 \\
\hline $2: 31$ & ...... & 32.24 & \\
\hline $2: 32$ & $\ldots$. & 32.28 & \\
\hline $2: 33$ & $\ldots \ldots$ & 32.325 & \\
\hline $2: 34$ & ..... & 32.35 & 25.15 \\
\hline $2: 3 \overline{5}$ & $\ldots$. & 32.365 & \\
\hline $2: 36$ & .... & 32.37 & \\
\hline $2: 37$ & ..... & 32.38 & \\
\hline $2: 38$ & ..... & 32.395 & 25.25 \\
\hline $2: 39$ & ..... & 32.405 & \\
\hline $2: 40$ & $\ldots \ldots$ & 32.45 & \\
\hline $2: 41$ & $\ldots$. & 32.50 & \\
\hline $2: 42$ & $\ldots \ldots$ & 32.56 & \\
\hline $2: 43$ & $\ldots \ldots$ & 32.61 & \\
\hline $2: 44$ & ..... & 32.665 & 25.2 \\
\hline $2: 45$ & ..... & 32.72 & \\
\hline $2: 46$ & $\ldots .$. & 32.78 & \\
\hline $2: 47$ & & 32.845 & \\
\hline \multirow[t]{2}{*}{ 3:06 } & 31.53 & 32,62 & \\
\hline & & & \\
\hline
\end{tabular}

Cooling of calorimeters, R., $0.46 \mathrm{C}$. in forty-three minutes, L., $0.225 \mathrm{C}$. in nineteen minutes. Volume of right hand, 572 c.c., of left hand 542 c.c. Water equivalent of calorimeters with contents, R., 3,553, L., 3,529. Rectal temperature 37.6 C. Blood pressure left arm systolic 133 (palpation), 133 (stethoscope), 86 (sound gone). Another observation 133, 87 .

In the case of Frank D. a slight preponderance of flow in the left hand was observed, 10.18 grams per 100 c.c. per minute for the right hand and 10.54 grams for the left with room temperature $25.2 \mathrm{C}$. for the last 11 minutes before testing the vasomotor reaction. The ratio of the flows in the two hands is $1: 1.03$. Immersion of the hand in cold water caused a good and durable vasoconstriction in the left hand. Immersion of the right hand in warm water occasioned a great initial vasoconstriction in the left, lasting for three minutes, during which the flow was reduced to 3.38 grams per 100 c.c. per minute. This gave way suddenly, as is normally the case, to vasodilatation, the flow in the left hand reaching 10.81 grams per 100 c.c. per minute for the remaining eight minutes of immersion of the right in the warm water. It will be observed that the initial flow was only slightly surpassed.

Since in this case the paralysis is confined to one hand, no other part of the body being at all affected, and since it came on suddenly, the conclusion seems justified that it was a pressure palsy. It is known that the long supinator sometimes escapes in pressure paralysis of the musculo-spiral nerve. Obviously cutaneous nerves are only slightly involved, and vasomotor fibers for the cutaneous vessels would not in 
this case be affected to any appreciable extent. Moreover it has been stated that the radial nerve does not carry vasomotor fibers. ${ }^{6}$

Although this statement is probably based on too slight an experimental foundation and need not be taken literally, it is clear enough that in the case under consideration a difference in the flow in the two hands comparable to that observed in lesions affecting the brachial plexus could not be expected.

In a case of motor neuron disease without sensory deficiency (Mrs. Mary N.) the vasoconstrictor reflexes were found to be of quite normal intensity and of more than normal duration.

Mrs. Mary N., a tailoress, height 5 feet, 6 inches, aged 46, was admitted to the dispensary, Nov. 10, 1910, suffering from progressive muscular atrophy. Her left hand became very painful about September, 1909. About a month thereafter she noticed some atrophy of the thenar eminence and weakness of the hand. About Christmas, 1909, the right hand became similarly affected. The condition gradually progressed and now the right arm shows some atrophy of the deltoid and musculo-spiral paralysis in the forearm, and wrist-drop with some median paralysis as well. Some atrophy of the thenar eminence exists. On the left side there is atrophy of the thenar eminence and some weakness of flexors and extensors but no wrist-drop. No loss of reflexes is shown in either arm. Both wrists and hands are wasted. The grip of both hands is very weak. The left leg is smaller than right, and has been so, at any rate, from the age of 3 . It shows peroneal palsy with foot-drop and shortened Achilles tendon, yet she can walk well. Some pain is present along the spine at the base of the neck. Knee-jerk and Achilles reflex are exaggerated on the right side, absent on the left. Babinski's sign is noted in the left foot. There is no sensory disturbance, clonus, or Romberg's sign. The pupils react to light and accommodation. The blood gives a strongly positive Wassermann reaction. The spinal fluid shows 150 cells per c.c., practically all mononuclear. The Noguchi reaction is positive. Physical examination of thorax is negative. Treatment with mercurials and potassium iodid, also with salvarsan, was without result. The patient continued to come to the dispensary till January, 1913, her condition gradually growing worse.

On Narch 7, 1912, the blood flow in the hands was examined. Hands in bath at $2: 27 \pi / 2 \mathrm{p}$. m., in calorimeters at $2: 38$. At $2: 52$ the right hand was put into water at $8 \mathrm{C}$. At $3 \mathrm{p}$. m. right hand was put into water at $43 \mathrm{C}$., which caused the hand to tingle. At 3:07 right hand was dried and wrapped in warm cloth. At 3:14 right hand was removed from calorimeter. Pulse 116. Mouth temperature $37.6 \mathrm{C}$.

The blood flow in the right hand was 6.99 grams, and in the left 7.13 grams per 100 c.c. per minute with room temperature $23.6 \mathrm{C}$. Immersion of the right hand in cold water caused the flow in the left to fall to 3.70 grams. There was no increase during the whole time for which the right hand continued in the cold water (seven minutes). The vasoconstriction was therefore intense and durable. When the right hand was immersed in warm water the flow in the left was further diminished to 3.37 grams. The intensity and persistence of the reflex vasoconstriction in this case may pretty safely be taken to indi-

6. Simons, A.: Arch. f. Anat. u. Physiol., 1910, 559. 
cate that the lesion in the motor neurons has not extended to the vasomotor cells in the cord or to the efferent paths from them. Since the pathologic change appears to be a system disease affecting the motor neurons but sparing the sensory neurons, there is nothing strange in its avoiding the vasomotor neurons also.

Table 10.-Calorimetric Measurements in Case of Mrs. Mary N.

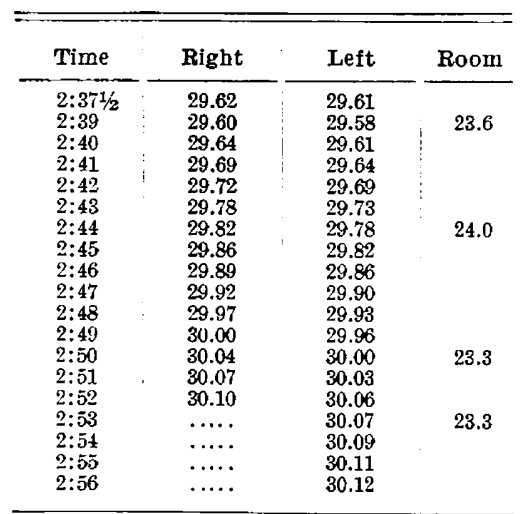

\begin{tabular}{|c|c|c|c|}
\hline Time & Right & Left & Room \\
\hline $2: 57$ & $\ldots$. & 30.13 & \\
\hline $2: 58$ & $\ldots$ & 30.14 & \\
\hline $2: 59$ & …... & 30.16 & \\
\hline $3: 00$ & ....... & 30.17 & \\
\hline $3: 01$ & …... & 30.18 & \\
\hline $3: 02$ & a... & 30.20 & \\
\hline $3: 03$ & ....... & 30.22 & \\
\hline $3: 04$ & …... & 30.22 & \\
\hline $3: 05$ & $\ldots$ & 30.24 & \\
\hline $3: 06$ & $\ldots$. & 30.24 & 23.9 \\
\hline $3: 07$ & $\ldots . .$. & 30.25 & \\
\hline $3: 08$ & …... & 30.28 & \\
\hline $\begin{array}{l}0.00 \\
3: 09\end{array}$ & …... & 30.30 & \\
\hline $3: 10$ & $\ldots .$. & $\begin{array}{l}50.00 \\
30.33\end{array}$ & \\
\hline $3: 11$ & ...... & 30.36 & \\
\hline $3: 12$ & …... & 30.37 & \\
\hline $3: 14$ & & 30.39 & \\
\hline $3: 15$ & 29.85 & & \\
\hline $3: 36$ & 29.64 & 30.16 & \\
\hline
\end{tabular}

Cooling of calorimeters, R., 0.25 C. in twenty-tree minutes, L., $0.23 \mathrm{C}$. in twenty-two minutes. Volume of right hand 340 c.c., of left hand 320 c.c.

Another case (Stanislas C.) in which a more or less general atrophy of the extremities, especially the anterior, existed presents certain interesting features. On account of the low degree of intelligence of the patient and his defect of speech the history of the case could not be clearly ascertained. Nor could the defects of sensation which seemed to exist be properly studied. Although this increased the difficulty of making a diagnosis and the true nature of the case was not cleared up, it will not be unprofitable, it is hoped, to quote the bloodflow findings, since they seemed capable of suggesting something toward the diagnosis and of supplementing precisely in such circumstances the examination of the sensory condition.

Stanislas C., a Polish laborer, aged 32, height 5 feet, 6 inches, was admitted to Lakeside Hospital, April 5. The patient complains that he cannot talk properly. Seven months before he was hit by a brick and has since been unable to swallow or talk. He did not lose consciousness. The right supraclavicular region shows a scar from the middle of the clavicle to the top of the scapula. The pupils react promptly to light and accommodation. The mouth tends to be drawn to the right. The tongue protrudes to the right and shows a fine tremor. The soft palate hangs to the right, and the left arch is higher than the right. Blood pressure, 124 systolic, 76 diastolic. General atrophy of muscles of extremities is shown. There is some contracture of the fingers of the right hand. No edema exists. Atrophy is noted of the muscles of the neck; the trapezius, spleriii, levator scapulae and serrati. His gait is shuffling but not ataxic. There is no hypotonus of the thigh. All the deep reflexes are exaggerated, except those of the right arm, in which the biceps, triceps and supinator reflexes are gone. There is ankle clonus, but no Babinski or Kernig's sign. Romberg's sign is 
very slight. The abdominal and cremasteric reflexes are increased. The right arm is smaller than the left, but the volume measurement showed the left hand somewhat atrophied in comparison with the right. Paresis is apparent of the left facial muscles. When asked to smile, the mouth is drawn to the right, but when made to laugh spontaneously both sides are equally used. The right side of the forehead wrinkles more than the left. The vocal cords move very poorly. Then sense of taste is disturbed. His intelligence is very low and does not permit satisfactory examination of sensation. He says that all sensations (temperature, pain, touch, vibration) are better felt over the right side (arm, leg and trunk) than over the left. It is doubtful whether this is true.

The blood flow in the hands was examined April 19. Hands were in bath at $2: 25 \mathrm{p}$. m., in calorimeters at $2: 39$. Mouth temperature $36.8 \mathrm{C}$. Pulse 72 . At $2: 50 \mathrm{x} / 2 \mathrm{p} . \mathrm{m}$. the left hand was immersed in water at $12 \mathrm{C}$. At $2: 55 \mathrm{x} / 2 \mathrm{p} . \mathrm{m}$. the left hand was dried and wrapped up. At $2.591 \% \mathrm{p}$. m. the left hand was put into water at $43.5 \mathrm{C}$. At 3:06 the left hand was put into water at $9 \mathrm{C}$. At $3: 13$ left hand was dried and wrapped up. At $3: 17$ right hand was removed from calorimeter.

Table 11.-Calorimetric Measurements in Case of Stanislas C.

\begin{tabular}{|c|c|c|c|}
\hline Time & Right & Left & Room \\
\hline $2: 38$ & 29.90 & 29.93 & \\
\hline $2: 40$ & 29.91 & 29.89 & 23.7 \\
\hline $2: 41$ & 29.94 & 29.90 & \\
\hline $2: 42$ & 29.97 & 29.89 & \\
\hline $2: 43$ & 29.99 & 29.90 & \\
\hline $2: 44$ & 30.02 & 29.90 & \\
\hline $2: 45$ & 30.07 & 29.90 & 23.8 \\
\hline $2: 46$ & 30.10 & 29.91 & \\
\hline $2: 47$ & 30.17 & 29.91 & 23.6 \\
\hline $2: 48$ & 30.21 & 29.91 & \\
\hline $2: 49$ & 30.25 & 29.92 & 23.6 \\
\hline $2: 50$ & 30.30 & 29.92 & \\
\hline $2: 51$ & 30.35 & $\ldots \ldots$ & 23.8 \\
\hline $2: 52$ & 30.39 & $\ldots$ & \\
\hline $2: 53$ & 30.43 & & \\
\hline $2: 54$ & 30.49 & $\ldots \ldots$ & 23.7 \\
\hline $2: 55$ & 30.57 & ..... & \\
\hline $2: 56$ & 30.60 & & \\
\hline $2: 57$ & 30.65 & & \\
\hline $2: 58$ & 30.71 & $\ldots$ & 23.6 \\
\hline $2: 59$ & 30.78 & & \\
\hline
\end{tabular}

\begin{tabular}{|c|c|c|c|}
\hline Time & Right & Left & Room \\
\hline $\begin{array}{l}3: 00 \\
3: 01 \\
3: 02 \\
3: 03 \\
3: 04 \\
3: 05 \\
3: 06 \\
3: 07 \\
3: 08 \\
3: 09 \\
3: 10 \\
3: 11 \\
3: 12 \\
3: 13 \\
3: 14 \\
3: 15 \\
3: 16 \\
3: 17 \\
3: 171 / 2 \\
3: 28\end{array}$ & $\begin{array}{l}30.80 \\
30.87 \\
30.94 \\
30.99 \\
31.07 \\
31.12 \\
31.18 \\
31.22 \\
31.27 \\
31.32 \\
31.39 \\
31.45 \\
31.49 \\
31.56 \\
31.60 \\
31.65 \\
31.70 \\
31.77 \\
\ldots \ldots . \\
31.63\end{array}$ & $\begin{array}{l}\ldots \ldots \\
\ldots \ldots \\
\ldots \ldots \\
29.68 \\
29.60\end{array}$ & $\begin{array}{l}23.6 \\
23.5 \\
23.5\end{array}$ \\
\hline
\end{tabular}

Cooling of calorimeters, R., 0.14 C. in eleven minutes, L., 0.32 C. in thirtyeight minutes. Volume of right hand in calorimeter 486 c.c., of left hand 422 c.c.

The flow in the right hand came out 7.0 grams and in the left only 1.47 grams per 100 c.c. per minute (for six minutes before the vasomotor test) the greatest difference between the two hands which has been observed in the whole series of observations. Measurement showed that the left hand was atrophied in comparison with the right. On immersing the left hand in cold water (for four minutes) the flow in the right increased to 7.85 grams per 100 c.c. per minute. When the left hand was dried and wrapped up, the flow in the right hand rose to 9.55 grams, to increase further to 10.28 grams on immersion of the left hand in warm water. A subsequent immersion of the left hand in cold water produced no effect on the flow unless to keep it stationary, and when the left hand was again wrapped up the flow in the right increased to 10.88 grams. These anomalous results in the reflex vaso- 
motor tests have scarcely any parallel in our series of observations. The most obvious explanation would be that the left hand was insensitive to cold, and the entire passivity of the patient when the hand was immersed in water at $9 \mathrm{C}$., which usually produces some discomfort, lends support to the suggestion. The initial vasoconstriction produced by immersion of the contralateral hand in warm water was also absent in this case, and again the suggestion is plausible that the left hand was insensible to warmth. The steady increase in the flow of the right hand during the whole course of the vasomotor tests would then be due simply to a spontaneously increasing vasodilatation unaffected by impulses from the left hand. While it would be rash to lay stress on isolated observations of this kind, it may be further pointed out that the marked deficiency of the blood flow in the left hand as compared with the right would agree well with a suggestion made when the diagnosis was being considered, that the general condition was superposed on an old left-side hemiplegia. For as we shall see directly, in the hemiplegias examined there was always a deficiency in blood flow in the paralyzed hand. The paresis of the left side of the face would also fit in with this. On the other hand the apparent absence of reflex vasomotor response in the right hand when the left was immersed in warm or cold water would agree with another suggestion made, that a syringomyelia (of the bulb) existed. In any case it seems reasonably clear that in circumstances in which the subjective response of the patient to warmth and cold cannot be studied information might be obtained by an objective method, namely, the study of the vasomotor reflex response.

\section{HEMIPLEGIA}

In the four cases of hemiplegia examined the flow in the paralyzed hand was always inferior to that in the normal hand. In C., a man aged 57, with hemiplegia of nine years' standing (paralysis of the left side of the face, left arm and leg) from which there had been very little recovery, the flow in the right hand was 9.15 grams and in the left only 4.67 grams per 100 c.c. per minute, with room temperature $22.2 \mathrm{C}$. During immersion of the right hand in warm water the flow in the left was 4.31 grams per 100 c.c. per minute for a period of nine minutes, and exactly the same during immersion of the right hand in cold water for a period of seven minutes. In this case there was no question of any defect of conduction in the afferent segment of the reflex vasomotor arc, since it was the normal hand which was subjected to the warmth and cold stimulation, and these sensations were perfectly perceived. The absence of the vasomotor reflex in this old-standing paralysis was interpreted as probably due to anatomic changes in the vessels of the atrophied left hand, including changes in the efferent 
vasomotor nerves of the hand and their terminations. The protocol of the case has already been published. ${ }^{7}$ In the other cases of hemiplegia in which the vasomotor reflexes were examined, evidence was obtained of the activity of the vasomotors of the paralyzed hand, reflex vasoconstriction, however, predominating over reflex vasodilatation.

Mrs. Eva M., aged 56, was admitted to the City Hospital, Sept. 11, 1911, with hemiplegia (left side). On September 5 she lost control of left hand, arm, and leg; fell to the floor but was at no time unconscious and retained the power of speech. When admitted the patient's face seemed unaffected; the tongue protruded in the median line. There was no paralysis of the palate. Complete loss of power and marked loss of tone in arm and leg were noted. The biceps and triceps reflexes of the left arm were absent. The knee-jerk was absent. Babinski's sign was present on the left side. Sense of position was lost in the left arm and leg. The sense of heat and cold was intact in the left arm and left leg above a level $4 \mathrm{~cm}$. below the knee. Pain sense was lost in the left arm below the shoulder and in the left leg below the knee. Some loss of pain sensibility was found between the left knee and the hip.

The blood flow in the hands was examined April 16, 1912. At this time there had been noticeable improvement in the left leg, but not in the arm or hand. The hands were in bath at $3: 21 \mathrm{p}$. m., in calorimeters at $3: 32$, out of calorimeters at 3:52. Mouth temperature $37.45 \mathrm{C}$. Pulse 104. The left hand as it hung down in the water pained her somewhat and therefore the vasomotor reaction was not tested.

TABle 12.-Calorimetric Measurements in Case of Mrs. Eva M.

\begin{tabular}{c|c|c|c}
\hline Time & Right & Left & Room \\
\hline $3: 33$ & 30.53 & 30.41 & 23.7 \\
$3: 34$ & 30.50 & 30.43 & \\
$3: 35$ & 30.55 & 30.46 & \\
$3: 36$ & 30.59 & 30.48 & \\
$3: 37$ & 30.62 & 30.50 & \\
$3: 38$ & 30.635 & 30.52 & 22.7 \\
$3: 39$ & 30.65 & $\mathbf{3 0 . 5 2 5}$ & \\
$3: 40$ & 30.67 & $\mathbf{3 0 . 5 3}$ & \\
$3: 41$ & 30.69 & $\mathbf{3 0 . 5 3 5}$ & \\
$3: 42$ & 30.70 & 30.54 & \\
$3: 43$ & 30.72 & 30.555 & \\
\hline
\end{tabular}

\begin{tabular}{l|l|l|l}
\hline \hline Time & Right & Left & Room \\
\hline $3: 44$ & $\mathbf{3 0 . 7 6}$ & $\mathbf{3 0 . 5 8}$ & \\
$3: 45$ & 30.79 & 30.60 & 23.3 \\
$3: 46$ & $\mathbf{3 0 . 8 1}$ & 30.61 & \\
$3: 47$ & $\mathbf{3 0 . 8 4 5}$ & 30.63 & \\
$3: 48$ & 30.88 & 30.645 & \\
$3: 49$ & 30.90 & 30.66 & \\
$3: 50$ & 30.93 & 30.68 & \\
$3: 51$ & 30.95 & 30.70 & \\
$3: 52$ & 30.99 & 30.73 & \\
$4: 02$ & 30.88 & 30.63 & \\
& & & \\
\hline
\end{tabular}

Cooling of calorimeters in ten minutes, R., 0.11 C., L., $0.10 \mathrm{C}$. Volume of right hand 334 c.c., of left hand 328 c.c. Water equivalent of calorimeters with contents, R., 3,362, L., 3,357.

The flow in the right hand in Mrs. Eva M. was 6.30 grams and in the paralyzed left hand 4.38 grams per 100 c.c. per minute with average room temperature $23 \mathrm{C}$.

George H., a man aged about 40 years, with typical motor aphasia and paralysis of the right arm and leg of 4 years' standing, had a blood flow of 7.26 grams per 100 c.c. per minute in the right hand and 9.82 grams in the left hand with room temperature $26.5 \mathrm{C}$. The ratio between the flows in the two hands was $1: 1.35$. During immersion of the left hand in cold water the flow in the right hand sank to 5.04 grams for the first three minutes and then increased to 7.93 grams per

7. Heart, 1911, iii, 81. 
100 c.c. per minute for the next seven minutes. Immersion of the left hand in warm water coincided with a further and persistent diminution of the flow in the right to 5.74 grams. It is possible that the vasoconstriction was merely that not inf requently seen at the close of an experiment and does not represent an abnormally great prolongation of the initial vasoconstriction produced by the application of warmth to the contralateral hand. But the duration of the experiment was by no means great and it is at the end of long experiments that spontaneous and long-lasting diminution in the flow is apt to be witnessed. It seems more probable that there is an abnormal tendency to vasoconstriction. in the paralyzed hand.

A week later, the flow was again measured in George $\mathrm{H}$. and came out 9.38 grams for the right hand, and 13.21 grams for the left with room temperature $25.5 \mathrm{C}$. The ratio between the flows was $1: 1.40$, practically the same as at the previous examination. This indicates that the increase in the flow was due mainly at least to increased action of the heart and it is rather curious that the ratio of the pulse frequencies $(1: 1.26)$ agrees almost exactly with the ratio of the blood flows in the paralyzed hand at the two examinations $(1: 1.29)$. If the hand flows in this patient can be taken as an index of the heart output, which is justifiable at any rate so far as the absence of anemia is concerned, ${ }^{8}$ this result would support the conclusion of Yandell Henderson $^{9}$ that with slow heart rates the minute output is proportional to the pulse frequency. There is no reason for thinking that the increased hand flows are due to a vasodilatation affecting the two hands in exactly the same proportion. In any case the external temperature could not be responsible for such an increase as it was about a degree lower at the second examination.

The flow in the feet of George $H$. was also examined on July 25, and came out 1.63 grams per 100 c.c. per minute for the right foot and 1.77 grams for the left. These flows in proportion to the hand flows are considerably below the normal.

George H. was admitted to the City Hospital, Oct. 5, 1909, with motor aphasia and paralysis of right arm and leg. He became paralyzed in 1908. When admitted he was unable to protrude the tongue. The right side of chest was markedly smaller than the left. There was a slight increase in the deep reflexes in the right arm and leg. The spinal fluid, 40 drops to minute, was clear, with 2 to 4 white cells to the c.c. and no Noguchi reaction. The blood flow in the hands was examined on July 18, and in the hands and feet on July 25,1912 . At this time aphasia is still complete. He seems to understand everything, but can only express assent or dissent by gestures. He can lift his arm to some extent but cannot move his left hand. He walks with a crutch and can stand by holding the back of a chair slightly. He can protrude the tongue easily in the median line and he can write. The knee-jerk is stronger on the

8. Jour. Exper. Med., 1913, xviii, 113.

9. Am. Jour. Physiol., 1913, xxxi, 288. 
right side than on the left. Ankle clonus is present on the right but not on the left side. There is no defect of sensation. Some external squint of right eye and diplopia is present. No ptosis exists.

Blood flow examination of George $H$., July 18, 1912: Hands were in bath at $2: 04 \mathrm{p}$. m., in calorimeters at $2: 15$. Some minutes elapsed before the right hand was got properly into the calorimeter. At 2:31 p. m. left hand was put into water at $8 \mathrm{C}$. Pulse 68 . At 2:41 left hand was put into water at $43 \mathrm{C}$. At $2: 51$ right hand was removed from calorimeter.

Table 13.-Calorimetric Measurements in Case of George $\mathrm{H}$.

\begin{tabular}{c|lll}
\hline Time & Right & Left & Room \\
\hline $2: 14$ & 31.52 & 31.45 & 26.5 \\
\cline { 1 - 2 } & 31.54 & 31.64 & \\
$2: 20$ & 31.58 & 31.68 & 26.6 \\
$2: 21$ & 31.61 & 31.75 & \\
$2: 22$ & 31.64 & 31.79 & \\
$2: 23$ & 31.69 & 31.87 & 26.8 \\
$2: 24$ & 31.72 & 31.93 & \\
$2: 25$ & 31.76 & 31.98 & \\
$2: 26$ & 31.79 & 32.045 & \\
$2: 27$ & 31.825 & 32.08 & 26.7 \\
$2: 28$ & 31.87 & 32.14 & \\
$2: 29$ & 31.90 & 32.175 & \\
$2: 30$ & 31.935 & 32.24 & \\
$2: 31$ & 31.98 & 32.28 & \\
$2: 32$ & 32.005 & & \\
$2: 33$ & 32.025 & $\ldots .$. & 26.7 \\
$2: 34$ & 32.04 & & \\
$2: 35$ & 32.10 & & \\
\hline
\end{tabular}

\begin{tabular}{l|l|l|l}
\hline Time & Right & Left & Room \\
\hline $2: 36$ & 32.135 & & \\
$2: 37$ & 32.18 & & \\
$2: 38$ & 32.22 & $\ldots \ldots$ & 26.4 \\
$2: 39$ & 32.25 & & \\
$2: 40$ & 32.28 & & \\
$2: 41$ & 32.295 & & \\
$2: 42$ & 32.31 & & \\
$2: 43$ & 32.33 & $\ldots \ldots$ & 26.4 \\
$2: 44$ & 32.365 & & \\
$2: 45$ & 32.38 & & \\
$2: 46$ & 32.395 & $\ldots \ldots$ & 26.4 \\
$2: 47$ & 32.42 & & \\
$2: 48$ & 32.45 & & \\
$2: 49$ & 32.475 & & \\
$2: 50$ & 32.50 & & \\
$2: 51$ & 32.52 & & \\
$3: 18$ & 32.25 & 31.87 & \\
& & & \\
\hline
\end{tabular}

Cooling of calorimeters, R., $0.27 \mathrm{C}$. in twenty-seven minutes, L., $0.41 \mathrm{C}$. in forty-seven minutes. Volume of right hand 464 c.c., of left hand 500 c.c. Mouth temperature $36.95 \mathrm{C}$. Blood pressure left arm, systolic 90, 82 (sound gone). Another observation 92, 85 .

Blood flow examination of George H., July 25, 1912: Results on the flow in the feet are given in the general table.

The hands were in bath at $2: 46 \mathrm{r} / 2 \mathrm{p} . \mathrm{m}$., in calorimeters at $2: 56$, out of calorimeters at $3: 09$.

Table 14.-Calorimetric Measurements in Case of George $H$.

\begin{tabular}{l:l:ll}
\hline Time & Right & Left & Room \\
\hline 2:54 & 31.38 & 31.36 & 25.2 \\
$2: 57$ & 31.38 & 31.39 & \\
$2: 58$ & 31.43 & 31.47 & 25.4 \\
$2: 59$ & 31.49 & 31.58 & \\
$3: 00$ & 31.53 & 31.65 & 25.7 \\
$3: 01$ & 31.59 & 31.73 & \\
$3: 02$ & 31.66 & 31.795 & 25.5 \\
$3: 03$ & 31.72 & 31.865 & \\
\hline
\end{tabular}

\begin{tabular}{c|c|c|c}
\hline Time & Right & Left & Room \\
\hline $3: 04$ & 31.75 & 31.945 & 25.55 \\
$3: 05$ & 31.80 & 32.00 & \\
$3: 06$ & 31.85 & 32.075 & 25.7 \\
$3: 07$ & 31.89 & 32.165 & \\
$3: 08$ & 31.91 & 32.23 & 25.7 \\
$3: 09$ & 31.92 & 32.27 & \\
$3: 17$ & 31.82 & 32.17 & \\
& & & \\
\hline
\end{tabular}

Cooling of calorimeters in eight minutes, $0.10 \mathrm{C}$. for R. and L. Volume of right hand 455 c.c., of left 497 c.c. Water equivalent of hand calorimeters and contents, R., 3,459, L., 3,492. Rectal temperature 37.4 C.

Dennis H., a structural iron worker, aged 41 , was admitted to the City Hospital, June 19, 1911, with hemiplegia of the left side. Walking along the street on July 15, he fell unconscious and remained so about fifteen minutes. He had been a hard drinker; had gonorrhea and probably lues. No anemia was present (hemoglobin 100 per cent.). The tongue protruded in the median line. The head was held toward the right rather than the left. He was unable to move the left arm and leg. The patellar, Achilles, biceps and triceps reflexes on the left side were exaggerated. No Babinski sign or ankle clonus was 
present. Epicritic and protopathic sensations over left leg were gone. Deep sensibility was present. Epicritic, protopathic, and deep sensibility was present in the arm but was greatly diminished. The same was true over the left side of the neck and face. No loss of power was seen in the face. Systolic blood pressure varied from 140 to 118 during the period of observation. On April 11, 1912, the blood flow in the hands was measured. At this time the left leg had recovered considerably, although he still used it very little. The left hand and arm were still quite powerless.

For the first six minutes in the calorimeters the flow in the right hand was 2.84 grams and in the left 1.80 grams per 100 c.c. per minute. During the immersion of the hands in the calorimeters the flow continued to increase gradually in both hands but particularly in the left so that for the whole period of immersion in the calorimeters (seventeen minutes) the flows came out 4.19 grams and 3.75 grams per 100 c.c. per minute for the right and left hands respectively. For the last six minutes of this period the flows were 4.92 grams for the right and 4.80 grams for the left hand. This gradual increase of the flow is observed under two conditions, first, when the flow is permanently small, and secondly, when an initial vasoconstriction is present, due either to nervousness on the part of the patient or to an abnormal sensitiveness of the vasomotor mechanism to the procedures necessarily involved in the measurement. In the case of Dennis $H$. both of these circumstances probably conspired. That a considerable tendency to vasoconstriction exists in the paralyzed hand was shown in the tests of the vasomotor reflexes. When the right hand was immersed in cold water the flow in the left was reduced from 4.80 grams to 3.49 grams per 100 c.c. per minute for the first seven minutes, to rise to 5.90 grams per 100 c.c. per minute for the remaining seven minutes of immersion of the right hand in the cold water. This constitutes a fair reflex vasoconstriction, particularly considering the small initial flow, and it endures, if anything, longer than normal. The moderate vasodilatation which succeeded was rather diminished than increased by subsequent immersion of the right hand in warm water.

\section{TABES DORSALIS}

In the five cases of tabes examined, the flow in both hands and feet was found subnormal, the deficiency being greater in the feet than in the hands. The vasomotor reflexes were quite feeble. The poor reflex response is especially striking when coupled with distinct or even acute perception of the sensations of cold and warmth, as in the case of Joseph S.

Joseph S., a laborer, aged 54, was admitted to the City Hospital, August 5, with tabes dorsalis. He had had pain and "funny feelings" for five years in both legs. Says he cannot feel over the hands or feet, but feels pin pricks somewhat. He also complains of sphincter trouble, and has a history of gonorrhea and lues. The spinal fiuid, 120 drops per minute, 200 cells per c.c., shows 
a strongly positive Noguchi reaction. The pupils, pin point, react to accommodation. There is little if any reaction to light. The nasal septum is perforated. Heart examination is negative. There is marked arteriosclerosis. Knee-jerk, Achilles and cremasteric reflexes are absent. Romberg sign is marked. Muscular incoordination is shown.

The blood flow in the hands and feet was measured August 7. Pulse 124. Hands in bath at $1: 46 \mathrm{~T} / 2 \mathrm{p}$. m., in calorimeters at $1: 573 / 4 \mathrm{p}$. m. At $2: 12$ left hand immersed in water at $8.4 \mathrm{C}$. He feels that the water is cold and soon begins to complain of it, withdrawing the hand momentarily. At 2:24 left hand put into water at $42.8 \mathrm{C}$. At 2:35 right hand removed from calorimeter.

TABLE 15.-Calorimetric Measurements in Case of Joseph S.

\begin{tabular}{|c|c|c|c|}
\hline Time & Right & Left & Room \\
\hline $1: 57$ & 31.20 & 31.13 & \\
\hline $1: 59$ & 31.22 & 31.15 & 24.9 \\
\hline $2: 00$ & 31.26 & 31.18 & \\
\hline $2: 01$ & 31.295 & 31.20 & 25.1 \\
\hline $2: 02$ & 31.325 & 31.22 & \\
\hline $2: 03$ & 31.365 & 31.255 & \\
\hline $2: 04$ & 31.40 & 31.27 & 25.0 \\
\hline $2: 05$ & 31.43 & 31.295 & \\
\hline $2 ; 06$ & 31.46 & 31.315 & \\
\hline $2: 07$ & 31.495 & 31.35 & 25.1 \\
\hline $2: 08$ & 31.52 & 31.365 & \\
\hline $2: 09$ & 31.56 & 31.38 & 25.1 \\
\hline $2: 11$ & $\begin{array}{l}01.60 \\
31.605\end{array}$ & $\begin{array}{l}31.400 \\
31.43\end{array}$ & \\
\hline $2: 12$ & 31.63 & 31.45 & \\
\hline $2: 13$ & 31.67 & $\ldots$. & 25.0 \\
\hline $2: 14$ & 31.695 & & \\
\hline $2: 15$ & 31.705 & & \\
\hline $2: 16$ & 31.73 & & \\
\hline $2: 17$ & 31.76 & & \\
\hline
\end{tabular}

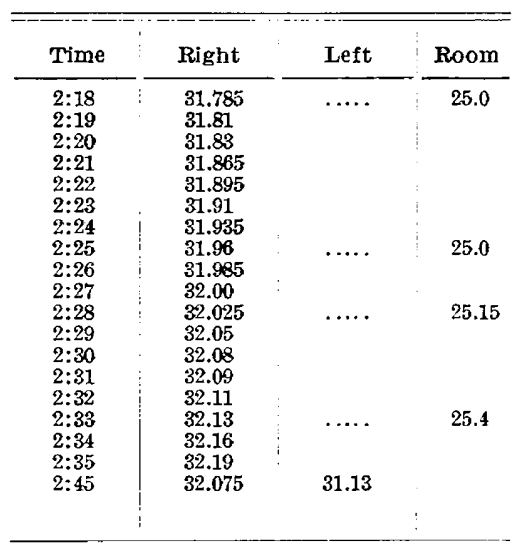

Cooling of calorimeters, R., $0.115 \mathrm{C}$. in ten minutes, L., $0.32 \mathrm{C}$. in thirtythree minutes. Volume of right hand in calorimeter 425 c.c., of left hand 441 c.c. $\mathrm{He}$ is right handed, but from the way in which he held his hand, a somewhat smaller proportion of the right hand was in the calorimeter than of the left. This is taken account of in the volume measurement.

The flow in the right foot in this patient was 0.76 gram and in the left foot 0.88 gram per 100 c.c. per minute with the relatively high room temperature $25 \mathrm{C}$. The flow in the right hand was 5.86 grams and in the left 4.33 grams with the same room temperature. Probably the inequality in the flows in the two hands is not so great as it appears to be. For, as has been mentioned in the protocol, the right hand was not inserted so deeply into the calorimeter as the left, and it has been shown that the flow per unit of volume is greater in the distal than in the proximal portions of the hand, corresponding with the relatively greater surface. However, in our study of diseases of the nervous system there have been numerous instances of the existence of inequalities of flow in the two hands or feet which could not be connected with any known cause. It may indeed be said that such inequalities are common features of those diseases. It has been suggested that vasomotor conditions, probably essentially connected with the pathology 
or pathologic physiology of the morbid state, are responsible for these inequalities. ${ }^{10}$

On immersion of the left hand (of Joseph S.) in cold water, which apparently caused him considerable discomfort, the flow in the right was but slightly changed, falling to 5.21 grams per 100 c.c. per minute for the first four minutes and then rising slightly again to 5.43 grams per 100 c.c. per minute for the remaining eight minutes of the immersion. This is truly an insignificant vasoconstrictor reaction. Immersion of the left hand in warm water caused a slight diminution of the flow in the right, to 5.22 grams per 100 c.c. per minute for the first five minutes, which then gave place to a correspondingly slight increase (to 5.48 grams for the next six minutes). Such slight reflex vasomotor effects have certainly rarely been observed in other conditions. It must be noted, however, that decided arteriosclerosis was present in this man and this condition is itself associated with relatively small vasomotor reflexes. ${ }^{11}$

In a case of tabes examined at the dispensary (Abe K.) the hand flows were only 1.27 grams for the right and 1.22 grams for the left, with room temperature $23 \mathrm{C}$. Probably the circulatory condition noted in the protocol was a factor in the small flow, as there was evidence of some loss of cardiac compensation (cyanosis, edema of legs and feet).

Abe $\mathrm{K}$., a waiter, aged 59 , was admitted to the dispensary January 30 . Six weeks ago he began to lose his sight and is now almost blind. For two months he has been unsteady on his feet, especially in walking at night. Some exophthalmos is noted. Slight ptosis of both eyes exists. The face and lips are cyanotic. The pupils are irregular, fixed, unequal, with no reaction to light or accommodation. His gait is uncertain, with left foot flapped. The kneejerk is much diminished. The Achilles reflex is absent. There is no Babinski sign. Edema of feet and legs is present, with hypotonus of muscles. Sensibility to touch, pain, heat and cold is diminished below the knees. The muscle sense is not good. There is incoordination of the hands. There is a slight Romberg sign. Examination of lungs is negative. The heart dulness extends $2 \mathrm{~cm}$. to the left of the nipple line. There is also increase of dulness to the right of the sternum. The aortic second sound is much accentuated. The edge of the liver is palpable 3 finger breadths below the costal margin on deep inspiration. The blood flow in the hands was measured on February 1.

W. B. C., a cigarmaker, aged 57, was admitted to Lakeside Hospital, November 8, with tabes dorsalis. He complains of difficulty in walking and ataxia, most marked in left leg. There are no sensory disturbances, except that he does not feel hot water on his feet unless it is pretty hot. Up to the present illness his eyesight has been good. There is external strabismus of the right eye. The pupils are unequal and irregular and do not react to light, but react to accommodation. Knee-jerk is absent. The hands are ataxic; he has difficulty in buttoning his clothes. Examination of heart and lungs is negative. The blood flow was examined November 11.

10. Paper XII of this series.

11. Stewart, G. N.: The Blood Flow in the Hands and Feet in Certain Diseased Conditions of the Vessels or of Their Nervous Mechanism, The ARchives Inr. Med., 1914, xiii, 177. 
The feet were in bath at $2: 23 \mathrm{p}$. m., in calorimeters at $2: 36$. At $3: 07$ the left foot was put into water at $44.3 \mathrm{C}$. He feels it comfortably warm. At $3: 19$ right foot was taken out of calorimeter. Pulse 84.

table 16-Calorimetric Meastrements in Case of W. B. C.

\begin{tabular}{|c|c|c|c|}
\hline Time & Right & Left & Room \\
\hline $2: 34$ & 31.33 & 31.26 & 20.9 \\
\hline $2: 37$ & 31.23 & 31.18 & 20.9 \\
\hline $2: 39$ & 31.22 & 31.17 & 20.9 \\
\hline $2: 41$ & 31.19 & 31.155 & \\
\hline $2: 43$ & 31.17 & 31.135 & 20.9 \\
\hline $2: 45$ & 31.14 & 31.13 & 21.2 \\
\hline $2: 47$ & 31.11 & 31.10 & 21.3 \\
\hline $2: 49$ & 31.09 & 31.085 & 21.3 \\
\hline $2: 51$ & 31.065 & 31.07 & 21.35 \\
\hline $2: 53$ & 31.04 & 31.06 & 21.4 \\
\hline $2: 55$ & 31.03 & 31.055 & 21.7 \\
\hline $2: 57$ & 31.01 & 31.05 & 21.8 \\
\hline $2: 59$ & 30.99 & 31.04 & 21.8 \\
\hline
\end{tabular}

\begin{tabular}{|c|c|c|c|}
\hline Time & Right & Left & Room \\
\hline $\begin{array}{l}3: 01 \\
3: 03 \\
3: 05 \\
3: 07 \\
3: 09 \\
3: 11 \\
3: 13 \\
3: 15 \\
3: 17 \\
3: 19 \\
3: 21 \\
3: 34\end{array}$ & $\begin{array}{l}30.97 \\
30.95 \\
30.925 \\
30.90 \\
30.89 \\
30.88 \\
30.865 \\
30.84 \\
30.825 \\
30.81 \\
30.74 \\
30.52\end{array}$ & $\begin{array}{c}31.03 \\
31.01 \\
30.99 \\
30.98 \\
\ldots \ldots \\
\ldots \ldots \\
\ldots \ldots \\
\ldots \ldots\end{array}$ & $\begin{array}{l}22.0 \\
22.0 \\
21.9 \\
\\
21.9 \\
21.8 \\
21.7 \\
21.7 \\
21.9\end{array}$ \\
\hline
\end{tabular}

Cooling of foot calorimeters in thrirteen minutes, R., 0.22 C., L., 0.21 C. Volume of right foot 925 c.c., of left foot 943 c.c. Water equivalent of feet calorimeters with contents, R., 3,660, L., 3,673.

The hands were in bath at 3:40 p. m., in calorimeters at 3:483/4. At 4:06 the left hand was put into water at $44.7 \mathrm{C}$. He feels it warm. At 4:20 left hand was put into water at $13 \mathrm{C}$. He feels it rather cold. Right hand taken out of calorimeter at $4: 29 \mathrm{p} . \mathrm{m}$.

TABLE 17.-Calorimetric Measurements in Case of W. B. C.

\begin{tabular}{|c|c|c|c|}
\hline Time & Right & Left & Room \\
\hline $3: 48$ & 31.75 & 31.76 & \\
\hline 3:50 & 31.74 & 31.75 & 23.3 \\
\hline $3: 51$ & 31.73 & 31.74 & 23.2 \\
\hline $3: 52$ & 31.73 & 31.74 & \\
\hline $3: 53$ & 31.74 & 31.75 & 23.2 \\
\hline $3: 54$ & 31.74 & 31.75 & 23.2 \\
\hline $3: 55$ & 31.75 & 31.75 & \\
\hline $3: 56$ & 31.76 & 31.755 & 23.1 \\
\hline $3: 57$ & 31.77 & 31.765 & \\
\hline $3: 58$ & 31.78 & 31.775 & \\
\hline $3: 59$ & 31.79 & 31.785 & 23.0 \\
\hline $4: 00$ & 31.80 & 31.80 & \\
\hline $4: 01$ & 31.81 & 31.82 & 22.9 \\
\hline $4: 02$ & 31.82 & 31.83 & \\
\hline $4: 03$ & 31.835 & 31.84 & 22.9 \\
\hline $4: 04$ & 31.85 & 31.85 & \\
\hline $4: 05$ & 31.86 & 31.86 & 23.0 \\
\hline $4: 06$ & 31.87 & 31.86 & \\
\hline $4: 07$ & 31.88 & & \\
\hline $4: 08$ & 31.89 & $\ldots$ & 23.0 \\
\hline 4:09 & 31.89 & & \\
\hline
\end{tabular}

\begin{tabular}{|c|c|c|c|}
\hline Time & Right & Left & Room \\
\hline $4: 10$ & 31.89 & .... & 22.9 \\
\hline $4: 11$ & 31.89 & & \\
\hline $4: 12$ & 31.90 & $\ldots$ & 22.7 \\
\hline $4: 13$ & 31.90 & & \\
\hline $4: 14$ & 31.91 & $\ldots$ & 22.8 \\
\hline $4: 15$ & 31,93 & & \\
\hline $4: 16$ & 31.95 & $\ldots$. & 22.9 \\
\hline $4: 17$ & 31.97 & & \\
\hline $4: 18$ & 31.99 & $\ldots$ & 22.9 \\
\hline $4: 19$ & 31.99 & & \\
\hline $4: 20$ & 32.01 & & \\
\hline $4: 21$ & 32.01 & $\ldots \ldots$ & 22.8 \\
\hline $4: 22$ & 32.02 & & \\
\hline $4: 23$ & 32.03 & $\ldots .$. & 22.5 \\
\hline $4: 24$ & 32.04 & & \\
\hline $4: 25$ & 32.05 & $\ldots .$. & 22.7 \\
\hline $4: 26$ & 32.06 & & \\
\hline $4: 27$ & 32.065 & $\ldots$ & 22.5 \\
\hline $4: 28$ & 32.07 & & \\
\hline $4: 29$ & 32.08 & & 22.7 \\
\hline $4: 38$ & 31.95 & 31.44 & \\
\hline
\end{tabular}

Cooling of hand calorimeters, R., 0.13 C. in nine minutes, L., 0.42 C. in thirty-two minutes. Volume of right hand 380 c.c., of left 388 c.c. Water equivalent of hand calorimeters with contents, R., 3,399, L., 3,405. Rectal temperature $36.90 \mathrm{C}$.

In W. B. C. the blood flow in the right foot was. 0.54 gram and in the left foot 0.87 gram per 100 c.c. per minute with room temperature 21.5 C. During immersion of the left foot (for a period of twelve minutes) in warm water, the flow in the right was 0.75 gram per 100 c.c. per minute. The hand flows before testing the vasomotor reaction 
were 5.42 grams for the right, and 5.05 grams for the left with room temperature $22.9 \mathrm{C}$. Immersion of the left hand in warm water reduced the flow in the right (for the first five minutes) to 4.01 grams per 100 c.c. per minute. For the remaining nine minutes of the period of immersion, the flow in the right hand rose to 6.16 grams per 100 c.c. per minute. A subsequent immersion of the left hand in cold water caused a diminution in the flow in the right to 3.26 grams but only for a single minute, the flow then rising for the remainder of the period of immersion to 5.3 grams per 100 c.c. per minute.

Gabriel M., a barber, aged 41, was admitted to Lakeside Hospital, November 13 , with the diagnosis of tabes. He complains of seeing double, that the left leg is weaker than the right and that he gets tired in walking. The patellar and Achilles reflexes are absent from both sides. The biceps and triceps reflexes are present in both arms. The plantar reflex is normal. There is marked hypotonus of the iliofemoral muscles with ataxia. There is ataxia also of the toes. Vibration is everywhere perceived. Hypesthesia to the needle is noted in both lower extremities, with great delay in transmission. Over the left leg the delay is fully two seconds. Romberg's sign is positive. The spinal fluid is clear under normal pressure, the cell count 8, Noguchi negative, Wassermann strongly positive. The grip of the hands is fairly strong. There is no incoordination of the hand movements. Sometimes a good deal of pain is present in the legs especially at night. The feet are habitually cold. Particulars of the first examination of the blood flow in the hands on November 17 are given in the general table.

Second examination of blood flow in Gabriel M., November 19: Hands in bath at 3:43 p. m., in the calorimeters at 3:52. At 4:10 p. m. the left hand was put into water at $43 \mathrm{C}$. At 4:20 p. m. the right hand was taken out of the calorimeter. Pulse 100 .

TABLE 18.-Calorimetric Measurements in Second Examination of GABRIEL M.

\begin{tabular}{l|l|l|l}
\hline Time & Right & Left & Room \\
\hline \multirow{2}{*nnn}{$3: 51$} & 31.73 & 31.64 & \\
$3: 53$ & 31.72 & 31.63 & 24.0 \\
$3: 54$ & 31.715 & 31.625 & 24.0 \\
$3: 55$ & 31.71 & 31.62 & \\
$3: 56$ & 31.71 & 31.62 & 24.0 \\
$3: 57$ & 31.705 & 31.61 & \\
$3: 58$ & 31.71 & 31.62 & 24.1 \\
$3: 59$ & 31.715 & 31.63 & \\
$4: 00$ & 31.72 & 31.635 & 24.1 \\
$4: 01$ & 31.72 & 31.63 & \\
$4: 02$ & 31.72 & 31.63 & 24.1 \\
$4: 03$ & 31.725 & 31.635 & \\
$4: 04$ & 31.73 & 31.64 & \\
$4: 05$ & 31.735 & 31.645 & 24.2 \\
$4: 06$ & 31.74 & 31.65 & \\
& & & \\
\hline
\end{tabular}

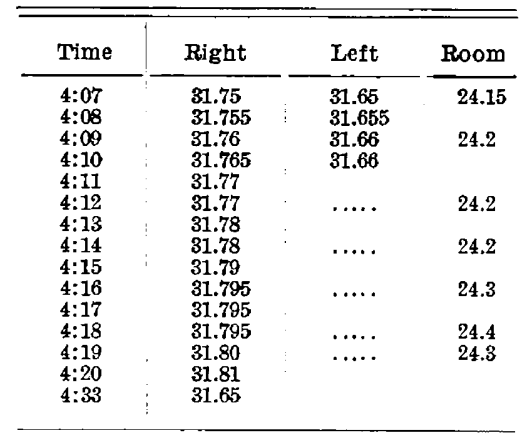

Cooling of hand calorimeters, R., $0.16 \mathrm{C}$. in thirteen minutes, L., $0.29 \mathrm{C}$. in twenty-three minutes. Volume of right hand, 424 c.c., of left 407 c.c. Water equivalent of calorimeters with contents, R., 3,434, L., 3,420. Rectal temperature $37.20 \mathrm{C}$.

Third examination of blood flow in Gabriel M., November 24. Feet in bath at $2: 45$ p. m., in calorimeters at $2: 56$. At $3: 44$ right foot put into water at $43 \mathrm{C}$. At 3:58 right foot put into water at $8.7 \mathrm{C}$. He felt it very cold at first. At $4: 12$ p. m. left foot taken out of calorimeter. 
TABLE 19.-Calorimetric Measurements in Third Examination of GABRIEL M.

\begin{tabular}{|c|c|c|c|}
\hline Time & Right & Left & Room \\
\hline $2: 55$ & 31.82 & 31.86 & 20.1 \\
\hline $2: 58$ & 31.63 & 31.66 & \\
\hline 3:00 & 31.54 & 31.57 & \\
\hline $3: 02$ & 31.47 & 31.52 & 20.3 \\
\hline 3:04 & 31.39 & 31.45 & 20.7 \\
\hline 3:06 & 31.32 & 31.39 & 20.8 \\
\hline $3: 08$ & 31.26 & 31.35 & 21.0 \\
\hline $3: 10$ & 31.21 & 31.29 & 21.0 \\
\hline $3: 12$ & 31.17 & 31.25 & 21.1 \\
\hline $3: 14$ & 31.12 & 31.20 & 21.2 \\
\hline $3: 16$ & 31.08 & 31.16 & 21.3 \\
\hline $3: 18$ & 31.05 & 31.13 & 21.4 \\
\hline $3: 20$ & 31.01 & 31.10 & 21.5 \\
\hline $3: 22$ & 30.98 & $\mathbf{3 1 . 0 7}$ & 21.7 \\
\hline $3: 24$ & 30.96 & 31.05 & 21.7 \\
\hline $3: 26$ & 30.94 & 31.03 & 21.9 \\
\hline $\begin{array}{l}3: 28 \\
3: 30\end{array}$ & $\begin{array}{l}30.92 \\
30.90\end{array}$ & $\begin{array}{l}31.01 \\
30.985\end{array}$ & 22.0 \\
\hline $3: 32$ & 30.895 & 30.97 & 22.1 \\
\hline $3: 34$ & 30.89 & 30.955 & 22.2 \\
\hline $3: 36$ & 30.88 & 30.95 & 22.2 \\
\hline
\end{tabular}

\begin{tabular}{|c|c|c|c|c|}
\hline Time & $!$ & Right & Left & Room \\
\hline $\begin{array}{l}3: 38 \\
3: 40 \\
3: 42 \\
3: 44 \\
3: 46 \\
3: 48 \\
3: 50 \\
3: 52 \\
3: 54 \\
3: 56 \\
3: 58 \\
4: 00 \\
4: 02 \\
4: 04 \\
4: 06 \\
4: 08 \\
4: 10 \\
4: 12 \\
4: 13 \\
4: 27\end{array}$ & 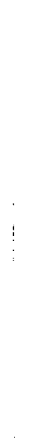 & $\begin{array}{l}30.88 \\
30.87 \\
30.87 \\
30.86 \\
30.795 \\
\ldots \ldots \\
\ldots \ldots \\
\ldots \ldots \\
\ldots \ldots \\
\ldots \ldots \\
\ldots \ldots \\
\ldots \ldots \\
\ldots \ldots \\
\ldots \ldots \\
\ldots \ldots \\
\ldots \ldots \\
\ldots \ldots . \\
30.09\end{array}$ & $\begin{array}{l}30.94 \\
30.93 \\
30.92 \\
30.90 \\
30.885 \\
30.87 \\
30.865 \\
30.86 \\
30.855 \\
30.85 \\
30.845 \\
30.835 \\
30.83 \\
30.82 \\
30.81 \\
30.80 \\
30.79 \\
30.77 \\
30.755 \\
30.52\end{array}$ & \begin{tabular}{|l}
22.3 \\
\\
\\
\\
22.4 \\
22.5 \\
22.6 \\
22.6 \\
22.6 \\
22.7 \\
22.8 \\
22.8 \\
\\
22.9 \\
23.1 \\
22.9
\end{tabular} \\
\hline
\end{tabular}

Cooling of foot calorimeters, R., $0.705 \mathrm{C}$. in forty-one minutes, L., $0.235 \mathrm{C}$. in fourteen minutes. Volume of right foot 1,092 c.c., of left 1,087 c.c. Water equivalent of foot calorimeters with contents R., 3,783, L., 3,779. Pulse 108.

Hands in bath at $4.33 \mathrm{~T} / 2 \mathrm{p} . \mathrm{m}$., in calorimeters at $4: 32$, out of calorimeters at $4: 43$.

TABLE 20.-CaLorimetric Measurements in Third Examination of GABRIEL M.

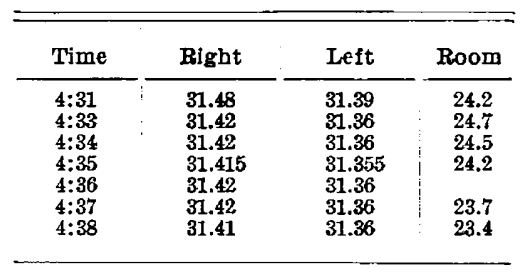

\begin{tabular}{|c|c|c|c|}
\hline Time & Right & Left & Room \\
\hline $\begin{array}{l}4: 39 \\
4: 40 \\
4: 41 \\
4: 42 \\
4: 43 \\
4: 49\end{array}$ & $\begin{array}{l}31.41 \\
31.41 \\
31.41 \\
31.41 \\
31.42 \\
31.32\end{array}$ & $\begin{array}{l}31.355 \\
31.255 \\
31.365 \\
31.365 \\
31.37 \\
31.28\end{array}$ & $\begin{array}{l}23.4 \\
23.9\end{array}$ \\
\hline
\end{tabular}

Cooling of hand calorimeters in six minutes, R., 0.10 C., L., 0.09 C. Rectal temperature $37.55 \mathrm{C}$. Volume of right hand 425 c.c., of left 390 c.c. Water equivalent of hand calorimeters with contents, R., 3,435, L., 3,407.

The flow in the right hand of Gabriel M. at the first examination was 1.0 gram, in the left 1.37 grams per 100 c.c. per minute with room temperature $22.6 \mathrm{C}$. Two days later the flows were 2.91 grams and 2.86 grams for the right and left hands respectively with the higher room temperature of $23.9 \mathrm{C}$. Immersion of the left hand in warm water caused scarcely any increase of flow in the right hand, which came out 3.07 grams per 100 c.c. per minute during the ten minutes of the period of immersion. The flow in the right foot at the same examination was $0.56 \mathrm{gram}$, and in the left $0.62 \mathrm{gram}$. The ratio of the combined foot flows to the combined hand flows was $1: 4.89$, indicating a relatively greater deficiency in the feet than in the hands. This is characteristic of all the cases of tabes examined. For a period 
of twenty-two minutes immersion of the right foot in warm water the flow in the left foot was slightly increased (to 0.89 gram per 100 c.c. per minute).

At the third examination the flow in the right hand of Gabriel M. was 2.77 grams and in the left hand 2.88 grams with room temperature $22.1 \mathrm{C}$. The flow in the right foot before testing of the vasomotor reflexes was 0.96 gram and in the left foot 0.73 gram. The ratio of the combined foot to the combined hand flows was $1: 3.93$. During immersion of the right foot in warm water the flow in the left foot (for the first four minutes of the immersion) sank to $0.65 \mathrm{gram}$, and then rose to 0.92 gram per 100 c.c. per minute for the remaining ten minutes of the immersion period. When the right foot was subsequently put into cold water the change was slight, the flow in the left foot being 0.84 gram per 100 c.c. per minute for the first four minutes of the immersion and 0.70 gram for the remaining ten minutes.

Table 21.-Calorimetric Measurements in Second Examination of JOHN M.

\begin{tabular}{|c|c|c|c|}
\hline Time & Right & Left & Room \\
\hline $2: 14$ & 31.79 & 31.68 & \\
\hline $2: 15$ & 31.77 & 31.67 & \\
\hline $2: 16$ & 31.78 & 31.68 & 23.8 \\
\hline $2: 17$ & 31.785 & 31.69 & \\
\hline $2: 18$ & 31.795 & 31.70 & \\
\hline $2: 19$ & 31.82 & 31.73 & 24.4 \\
\hline $2: 20$ & 31.85 & 31.76 & 24.2 \\
\hline $2: 21$ & 31.88 & 31.79 & \\
\hline $2: 22$ & 31.90 & 31.82 & \\
\hline $2: 23$ & 31.92 & 31.85 & \\
\hline $2: 24$ & 31.94 & 31.87 & 23.9 \\
\hline $2: 25$ & 31.98 & 31.90 & \\
\hline $2: 26$ & 32.00 & 31.93 & \\
\hline $2: 27$ & 32.025 & & 24.1 \\
\hline $2: 28$ & 32.05 & & \\
\hline $2: 29$ & 32.07 & ..... & 24.2 \\
\hline $2: 30$ & 32.09 & & \\
\hline
\end{tabular}

\begin{tabular}{|c|c|c|c|}
\hline Time & Right & Left & Room \\
\hline $\begin{array}{l}2: 31 \\
2: 32\end{array}$ & $\begin{array}{l}32.115 \\
32.15\end{array}$ & $\ldots$ & 24.4 \\
\hline $2: 33$ & 32.185 & $\cdots$ & 24.7 \\
\hline $2: 34$ & 32.21 & & \\
\hline $2: 35$ & 32.24 & & \\
\hline $2: 36$ & 32.28 & & \\
\hline $2: 37$ & 32.31 & .... & 24.8 \\
\hline $2: 38$ & 32.335 & & \\
\hline $2: 39$ & 32.37 & $\ldots$ & 24.5 \\
\hline $2: 40$ & 32.395 & & \\
\hline $\begin{array}{l}2: 41 \\
2: 42\end{array}$ & $\begin{array}{l}32.42 \\
32.45\end{array}$ & $\ldots$ & 24.0 \\
\hline $2: 43$ & 32.49 & $\ldots$ & 23.4 \\
\hline $2: 44$ & 32.52 & $\ldots$. & 23.4 \\
\hline $2: 45$ & 32.57 & $\ldots$ & 23.8 \\
\hline $2: 52$ & 32.47 & 31.55 & \\
\hline
\end{tabular}

Cooling of hand calorimeters, R., $0.10 \mathrm{C}$. in seven minutes, L., $0.38 \mathrm{C}$. in twenty-six minutes. Volume of right hand 426 c.c., of left 399 c.c. Water equivalent of hand calorimeters with contents, R., 3,436, L., 3,414. Pulse 96.

John M., a laborer, aged 45, was admitted December 2 at Lakeside Hospital with the diagnosis of tabes, complaining of incontinence of urine and trouble in walking. A history was given of gonorrhea. He says he was bit in the arm twenty-eight years ago by a person supposed to have had lues. He denies having had chancre. His present illness seems to have commenced fourteen years ago. The reflexes are hypo-active in the biceps and supinator of both arms. The lower extremities are ataxic. The patellar and ankle reflexes are absent, also the plantar reflexes. There is no Babinski or Kernig's sign. Romberg's sign is positive. He feels a point on the feet but the response is slow. He walks fairly well, better than some time ago, he says. The pupils are equal, central and regular, but do not react to light and very sluggishly to accommodation. The skin of the nose is covered entirely by scar tissue; the septum is deficient posteriorly. Blood examination, erythrocytes $4,976,000$, white blood corpuscles 6,200, hemoglobin 80 per cent. The blood flow was examined on 
December 3 and December 8. The particulars of the flow in the feet at first examination of John M. are given in the general table.

Second examination of blood flow in John M., Dec. 8, 1914. Hands were in bath at $2: 05 \mathrm{p} . \mathrm{m}$., in calorimeters at $2: 14 \mathrm{~T} / 2$. At $2: 26 \mathrm{p}$. m. the left hand was put into water at $8 \mathrm{C}$. At $2: 36 \mathrm{p}$. m. the left hand was put into water at 43.1 C. At 2:45 p. m. the right hand was taken out of the calorimeter.

The feet were in bath at 2:55 p. m., in calorimeters at $3: 06$. At $3: 41 \mathrm{p} . \mathrm{m}$. right foot was put into water at $8.3 \mathrm{C}$. He feels it pretty cold. At 3:55 p. m. left foot taken out of calorimeter.

TABle 22.-Calorimetric Measurements in Second Examination of JOHN M. (FEET)

\begin{tabular}{|c|c|c|c|}
\hline Time & Right & Left & Room \\
\hline $3: 05$ & 32.28 & 32.33 & 24.8 \\
\hline $3: 08$ & 32.18 & 32,25 & 24.8 \\
\hline $3: 09$ & 32.15 & 32.20 & 24.9 \\
\hline $3: 11$ & 32.12 & 32.17 & \\
\hline $3: 13$ & 32.11 & 32.16 & 24.5 \\
\hline $3: 15$ & 32.10 & 32.155 & \\
\hline $3: 17$ & 32.09 & 32.145 & 24.8 \\
\hline $3: 19$ & 32.07 & 32.13 & 24.9 \\
\hline $3: 21$ & 32.05 & 32.11 & 24.7 \\
\hline $3: 23$ & 32.02 & 32.085 & \\
\hline $3: 2.5$ & 32.00 & 32.07 & 24.5 \\
\hline $3: 27$ & 32.00 & 32.065 & \\
\hline $3: 29$ & 31.99 & 32.06 & 24.5 \\
\hline $3: 31$ & 31.985 & 32.06 & 24.7 \\
\hline
\end{tabular}

\begin{tabular}{|c|c|c|c|}
\hline Time & Right & Left & Room \\
\hline $3: 33$ & 31.98 & 32.055 & 24.8 \\
\hline $3: 35$ & 31.98 & 32.055 & 24.8 \\
\hline $3: 37$ & 31.97 & 32.06 & 24.8 \\
\hline $3: 39$ & 31.97 & 32.06 & \\
\hline $3: 41$ & 31.96 & 32.065 & 24.8 \\
\hline $3: 43$ & 31.88 & 32.065 & 24.7 \\
\hline $3: 45$ & ..... & 32.06 & 24.8 \\
\hline $3: 47$ & ..... & 32.055 & \\
\hline $3: 49$ & $\ldots \ldots$ & 32.05 & 24.5 \\
\hline $3: 51$ & $\ldots$ & 32.045 & 24.6 \\
\hline $3: 53$ & $\ldots$ & 32.04 & 24.8 \\
\hline $3: 55$ & ..... & 32.04 & \\
\hline $3: 58$ & $\ldots \ldots$ & 31.97 & \\
\hline 4:04 & 31.51 & 31.86 & \\
\hline
\end{tabular}

Cooling of foot calorimeters, R., $0.37 \mathrm{C}$. in twenty-one minutes, L., $0.11 \mathrm{C}$. in six minutes. Rectal temperature, $37.65 \mathrm{C}$. Volume of right foot, 1,006 c.c., of left, 1,001 c.c. Water equivalent of foot calorimeters with contents, R., 3,720, L., 3,716.

In John M. at the first examination the flows in the right and left foot respectively, before the vasomotor reflexes were tested, were 1.27 grams and 1.28 grams per 100 c.c. per minute, with room temperature $24.2 \mathrm{C}$. For a period of twelve minutes immersion of the right foot in cold water, the flow in the left was reduced to 0.95 gram per 100 c.c. per minute. Subsequent immersion of the right foot in warm water for a period of fourteen minutes caused an increase of the flow in the left to 1.52 grams per 100 c.c. per minute. Five days later the flow in the right hand was found to be 6.60 grams and in the left 7.57 grams with room temperature $24 \mathrm{C}$. When the left hand was put into cold water the flow in the right fell to 6.46 grams per 100 c.c. per minute for the first five minutes and then rose for the remaining five minutes of the period of immersion of the left hand, to 8.47 grams per 100 c.c. per minute, an insignificant reaction. When the left hand was subsequently immersed in warm water the flow in the right hand was only increased to 8.79 grams per 100 c.c. per minute for the whole nine minutes of the period of immersion. At the same examination the flow in the right foot came out, before the vasomotor reflexes were tested, 1.35 grams per 100 c.c. per minute and that in the left foot 1.57 grams, with room temperature $24.7 \mathrm{C}$. The ratio of the combined foot flow to the combined hand flow was $1: 4.85$. The room was warm and the 
patient perspiring, so that the flows both in hands and feet are really more deficient than the actual numbers would suggest, and the same is true for the foot flows at the first examination. When the right foot was immersed in cold water the flow in the left foot was only slightly changed, falling to 1.39 grams per 100 c.c. per minute for the whole fourteen minutes of the immersion.

The case of Joseph $\mathrm{K}$. is of interest, inasmuch as the suggested diagnosis of malingering was not, as regards the symptoms described in the legs, supported by the blood flow examination, which, on the contrary, indicated a real pathologic condition.

Joseph K., a laborer, aged 48, was admitted to the hospital June 17. There appears to be delayed sensation in the extremities. He says that he does not feel heat or vibratory sensation in the thighs. Pin pricks are apparently not well recognized. Knee-jerk and Achilles reflex are strong. He complains of pain in the left leg. Says he has cold sweats on legs and feet at night in bed. His legs feel cold to his hand, although he expects them to be warm since they are covered with sweat. He pinches his calf and says he feels nothing there. A zone on the calves is apparently anesthetic to contact. In front on the shins

Table 23.-Calorimetric Measurements in Case of Joseph $\mathrm{K}$.

\begin{tabular}{l|l|l|l}
\hline Time & Right & Ieft & Room \\
\cline { 1 - 3 } $1: 53$ & 31.13 & 31.12 & \\
$1: 55$ & 31.12 & 31.125 & 27.2 \\
$1: 56$ & 31.16 & 31.16 & \\
$1: 57$ & 31.21 & 31.22 & \\
$1: 58$ & 31.26 & 31.27 & 27.2 \\
$1: 59$ & 31.31 & 31.325 & \\
$2: 00$ & 31.36 & 31.36 & \\
$2: 01$ & 31.42 & 31.41 & 27.3 \\
$2: 02$ & 31.49 & 31.47 & \\
$2: 03$ & 31.54 & 31.525 & \\
$2: 04$ & 31.605 & 31.585 & 27.3 \\
$2: 05$ & 31.68 & 31.64 & \\
$2: 06$ & 31.73 & 31.60 & \\
$2: 07$ & 31.76 & & \\
$2: 08$ & 31.79 & $\ldots .$. & 27.3 \\
$2: 09$ & 31.80 & & \\
$2: 10$ & 31.825 & & \\
$2: 11$ & 31.87 & & \\
& & & \\
& & &
\end{tabular}

\begin{tabular}{|c|c|c|c|}
\hline Time & Right & Left & Room \\
\hline $2: 12$ & 31.905 & & \\
\hline $2: 13$ & 31.925 & .... & 27.4 \\
\hline $2: 14$ & 31.96 & (6. & \\
\hline $2: 15$ & 31.995 & & \\
\hline $2: 16$ & 32.025 & ..... & 27.4 \\
\hline $2: 17$ & 32.05 & & \\
\hline $2: 18$ & 32.08 & & \\
\hline $2: 19$ & 32.12 & $\ldots$ & 27.5 \\
\hline $2: 20$ & 32.165 & & \\
\hline $2: 21$ & 32.205 & & \\
\hline $2: 22$ & 32.26 & & \\
\hline $2: 23$ & 32.30 & $\ldots$ & 27.55 \\
\hline $2: 24$ & 32.365 & . & \\
\hline $2: 25$ & 32.42 & & \\
\hline $2: 26$ & 32.48 & & 27.55 \\
\hline $2: 27$ & 32.545 & & \\
\hline $2: 33$ & 32.49 & 31.505 & \\
\hline
\end{tabular}

Cooling of calorimeters, R., $0.055 \mathrm{C}$. in six minutes, L., $0.195 \mathrm{C}$. in twentyseven minutes. Volume of right hand 495 c.c., of left hand 479 c.c. Water equivalent of calorimeters with contents, R., 3,491, L., 3,478. Rectal temperature $37.55 \mathrm{C}$.

at this level he feels contact, as also on the patellae and on the feet. He feels warm water on the feet. He says his hand "shortens" when he tries to write. His pupils react to light and accommodation. The chest examination reveals nothing special. Temperature normal. Blood examination on June 24 gave erythrocytes 5,120,000; leukocytes 9,400; hemoglobin 85 per cent. Two Wassermann tests were negative for blood, as also the Wassermann and Noguchi reactions for spinal fluid. On June 26 pin pricks were better appreciated over the thighs; the knee-jerks were not strong, but were equal on the two sides. The patient was discharged on July 3 "cured," with a suggestion that he was malingering. Blood flow in the hands and feet was examined on June 26. The day was warm.

Hands in bath at $1: 41 \mathrm{p} . \mathrm{m}$, in calorimeters at $1: 54 \mathrm{I} / 3 \mathrm{p}$. m. At $2: 06 \mathrm{p} . \mathrm{m}$. left hand immersed in cold water $(8.5 \mathrm{C}$.). He says he feels the water very 
cold. At $2: 16$ p. m. left hand put into water at $41.4 \mathrm{C}$. At $2: 27$ the right hand taken out of calorimeter.

The flow in the right hand in Joseph $\mathrm{K}$. was 8.94 grams and in the left 8.75 grams per 100 c.c. per minute with room temperature $27.3 \mathrm{C}$. For the man's age and the high room temperature, these flows are fair but by no means large, and the slight preponderance in the right hand is entirely normal. The vasomotor reflexes in the hand both to cold and warmth were also normal in intensity and duration. In the feet, on the contrary, the flows came out extremely small, especially taking into account the high room temperature $(0.50$ grams for the right and 0.54 gram per 100 c.c. per minute for the left foot, with room temperature 26.4 C.). This is quite in agreement with the patient's statement as to the coldness of his feet. Also there was total absence of any vasomotor reflex in the left foot when the right was immersed for ten minutes in warm water, the flow remaining unchanged ( 0.53 gram $)$. While the patient might have showed some temporary improvement in his not very obtrusive symptoms during his stay in the hospital, it seems unlikely that such definite blood flow results for the feet should be devoid of significance. They at any rate would suggest the necessity in such a case of renewed careful examination of the patient before the suggestion of malingering could be accepted.

In Fred L., a man aged 22, with a glioma of the occipital lobe, the striking feature of the blood-flow examination was the great intensity of the contralateral vasomotor reflexes both to heat and cold. Two examinations were made within eight days and this was clearly seen at both. It is a plausible suggestion that the increased intracranial pressure, of which there were evident symptoms, may have rendered the vasomotor centers hyperexcitable. It is possible also that the rather small flows for the age of the patient might have been due to a peripheral vasoconstriction produced in this way in the interest of the brain circulation.

Fred. L. was first admitted to Lakeside Hospital, June 30, 1908. He complained of dizzy attacks and severe headache. The attacks occurred about once a week and varied in intensity. There was never any nausea or vomiting. Severe headaches had occurred nearly every day since his first trouble. Examination of the eyes showed choked disk and hemianopsia. He could not see objects at his right. Hearing, the same on both sides, was a little less acute than normal. Numerous lumbar punctures were made, and finally a decompression operation was done. Two years later he reported to the dispensary much improved. He again reported July 18, 1911, that occipital headache came on at night and prevented sleep. Only large doses of morphin quieted him at all. He was readmitted to the hospital, Oct. 8, 1912. Hemianopsia was present as before. The blood flow in the hands was twice examined (Nov. 18 and Nov. 26, 1912). On November 27 he left the hospital for Thanksgiving and returned on November 28 with severe headache and vomiting. On November 29 an operation was resolved on, during which he died. The necropsy showed a 
glioma with cystic degeneration in the left occipital lobe resting on the tentorium. The cyst measured about $5 \mathrm{~cm}$. by $3 \mathrm{~cm}$.

First blood flow examination of Fred. L.: Hands in bath at $3: 07$ p. m., in calorimeters at $3: 20 \mathrm{r} / 2$. At $3: 38$ left hand immersed in water at $43 \mathrm{C}$. Pulse 88 . At 3:50 p. m. the left hand was put into water at $11.2 \mathrm{C}$. He feels the water very cold. At 4:02 right hand was removed from calorimeter.

table 24.-Calorimetric Measurements in Case of Fred. L.

\begin{tabular}{|c|c|c|c|}
\hline Time & Right & Left & Room \\
\hline $\begin{array}{l}3: 20 \\
3: 22 \\
3: 23 \\
3: 24 \\
3: 25 \\
3: 26 \\
3: 27 \\
3: 28 \\
3: 29 \\
3: 30 \\
3: 31 \\
3: 32 \\
3: 33 \\
3: 34 \\
3: 35 \\
3: 36 \\
3: 37 \\
3: 38 \\
3: 39 \\
3: 40 \\
3: 41 \\
3: 42\end{array}$ & \begin{tabular}{|l}
30.44 \\
30.37 \\
30.38 \\
30.38 \\
30.385 \\
30.41 \\
30.43 \\
30.48 \\
30.52 \\
30.58 \\
30.60 \\
30.61 \\
30.63 \\
30.66 \\
30.69 \\
30.71 \\
30.71 \\
30.73 \\
30.74 \\
30.765 \\
30.80 \\
30.83
\end{tabular} & \begin{tabular}{|l|}
30.42 \\
30.40 \\
30.41 \\
30.42 \\
30.43 \\
30.47 \\
30.50 \\
30.53 \\
30.565 \\
30.58 \\
30.60 \\
30.62 \\
30.64 \\
30.68 \\
30.70 \\
$30.71 *$ \\
30.71 \\
30.70
\end{tabular} & $\begin{array}{l}22.0 \\
22.1 \\
22.1 \\
22.0 \\
22.0\end{array}$ \\
\hline
\end{tabular}

\begin{tabular}{|c|c|c|c|}
\hline Time & Right & Left & Room \\
\hline $3: 43$ & 30.88 & & \\
\hline $3: 44$ & 30.92 & & \\
\hline $3: 45$ & 30.96 & & \\
\hline $3: 46$ & 31.01 & & \\
\hline $3: 47$ & 31.06 & & \\
\hline $3: 48$ & 31.09 & 30.58 & \\
\hline $3: 49$ & 81.12 & & \\
\hline $3: 50$ & 31.18 & & \\
\hline $3: 51$ & 31.18 & & \\
\hline $3: 52$ & 31.185 & & \\
\hline $3: 53$ & 31.19 & & \\
\hline $3: 54$ & 31.19 & $\ldots .$. & 23.0 \\
\hline & 31.19 & & \\
\hline $\begin{array}{l}3: 56 \\
3: 57\end{array}$ & $\begin{array}{l}31.195 \\
31.225\end{array}$ & $\ldots \ldots$ & 22.8 \\
\hline $3: 58$ & 31.245 & $\ldots$. & 22.5 \\
\hline $3: 59$ & 31.25 & $\ldots .$. & 22.1 \\
\hline $4: 00$ & 31.27 & & \\
\hline 4:01 & 31.28 & $\ldots .$. & 22.2 \\
\hline $4: 02$ & 31.31 & & \\
\hline $4: 12$ & 31.19 & & \\
\hline
\end{tabular}

Cooling of calorimeters in ten minutes, R., 0.12 C., L., $0.11 \mathrm{C}$. Volume of right hand 385 c.c., of left 377 c.c. His hands are thin. Water equivalent of calorimeters with contents, R., 3,403, L., 3,397. Rectal temperature 37.7 C.

$* \mathrm{He}$ is paying great attention to the preparations for the warm water test.

TABLE 25.-Calorimetric Measurements in Second Examination of FRED. L.

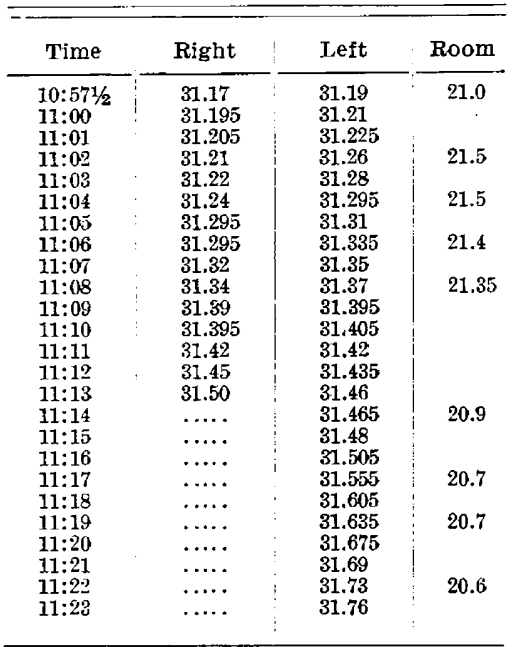

\begin{tabular}{|c|c|c|c|}
\hline Time & Right & Left & Room \\
\hline $\begin{array}{l}11: 24 \\
11: 25 \\
11: 26 \\
11: 27 \\
11: 28 \\
11: 29 \\
11: 30 \\
11: 31 \\
11: 32 \\
11: 33 \\
11: 34 \\
11: 35 \\
11: 36 \\
11: 37 \\
11: 38 \\
11: 39 \\
11: 40 \\
11: 41 \\
11: 42 \\
11: 43 \\
11: 44 \\
11: 45 \\
11: 46 \\
12: 02\end{array}$ & 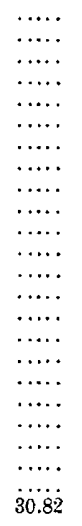 & $\begin{array}{l}31.785 \\
31.795 \\
31.80 \\
31.795 \\
31.80 \\
31.805 \\
31.81 \\
31.82 \\
31.82 \\
31.82 \\
31.815 \\
31.825 \\
31.835 \\
31.86 \\
31.875 \\
31.89 \\
31.90 \\
31.915 \\
31.935 \\
31.95 \\
31.965 \\
31.975 \\
31.99 \\
31.725\end{array}$ & $\begin{array}{l}20.7 \\
20.7\end{array}$ \\
\hline
\end{tabular}

Cooling of calorimeters, R., $0.68 \mathrm{C}$. in 49 minutes, L., $0.265 \mathrm{C}$. in sixteen minutes. Volume of right hand 389 c.c., of left 380 c.c. Water equivalent of calorimeters with contents, R., 3,406, L., 3,399. Rectal temperature $37.75 \mathrm{C}$. 
Second blood flow examination of Fred. L.: He says he is feeling better than at the previous examination though he was sick (vomiting) all yesterday morning. Hands were in bath at $10: 45 \mathrm{r} / 2 \mathrm{a}$. m., in calorimeters at $10: 58 \mathrm{r} / 2$. At $11: 13 \mathrm{a}$. $\mathrm{m}$. the right hand was put into water at $43 \mathrm{C}$. At 11:24 a. m. the right hand was put into water at $10.5 \mathrm{C}$. At $11: 35$ right hand was again immersed in water at $43 \mathrm{C}$. At 11:46 right hand was taken out of calorimeter. Pulse 100 .

At the first examination the flow in the right hand in Fred L. was 5.43 grams and in the left 4.80 grams per 100 c.c. per minute with room temperature $22 \mathrm{C}$. (ratio $1: 1.13$ ). Immersion of the left hand in warm water reduced the flow for the first two minutes in the right hand to 4.18 grams per 100 c.c. per minute. For the remaining ten minutes of the period of immersion the flow in the right hand rose to 8.28 grams per 100 c.c. per minute, a marked reflex vasodilatation. When the left hand was now immersed in cold water the flow in the right hand fell to 2.28 grams per 100 c.c. per minute for the first six minutes of the period of immersion. For the remaining six minutes of the period it rose somewhat but only to 4.84 grams. The reflex vasoconstriction was thus very intense and durable. At the second examination the flow for the right hand, before the vasomotor reaction was tested, was 6.15 grams per 100 c.c. per minute and for the left 5.49 grams with room temperature $21.4 \mathrm{C}$. (ratio $1: 1.12$, almost precisely the same as at the previous examination). The vasomotor reflex tests also showed intense and persistent effects.

In a young man ( J. S.), recovering from tetanus after antitoxin treatment, vasomotor reflexes fully as intense were observed. There was no direct evidence that this condition was due to the action of the tetanus toxin or antitoxin on the nervous system, but the extent of the crossed vasomotor reflexes was certainly notable.

table 26.-Calorimetric Measurements in Case of J. S.

\begin{tabular}{|c|c|c|c|c|c|c|c|}
\hline Time & Right & Left & Room & Time & Right & Left & Room \\
\hline $1: 37$ & 30.53 & 30.54 & \multirow{4}{*}{25.5} & $1: 54$ & 30.74 & \multirow{9}{*}{ - } & \multirow{9}{*}{26.0} \\
\hline $1: 39$ & 30.49 & 30.51 & & $1: 55$ & 30.795 & & \\
\hline $1: 40$ & 30.48 & 30.49 & & $1: 56$ & 30.83 & & \\
\hline $1: 41$ & 30.47 & 30.49 & & $1: 57$ & 30.89 & & \\
\hline $1: 42$ & 30.48 & $30 . \overline{5} 0$ & \multirow{5}{*}{26.0} & $1: 58$ & 30.935 & & \\
\hline $1: 43$ & 30.495 & 30.52 & & $1: 59$ & 30.995 & & \\
\hline $1: 44$ & 30.51 & $30 . \overline{4} 4$ & & $2: 00$ & 31.05 & & \\
\hline $1: 45$ & 30.585 & 30.56 & & $2: 01$ & 31.08 & & \\
\hline $1: 46$ & 30.58 & 30.61 & & $2: 02$ & 31.095 & & \\
\hline $1: 47$ & 30.61 & 30.64 & \multirow{3}{*}{25.9} & 2:03 & 31.10 & \multirow[t]{2}{*}{$\ldots}$. & \multirow[t]{2}{*}{26.0} \\
\hline $1: 48$ & 30.63 & 30.67 & & $2: 04$ & 31.16 & & \\
\hline $1: 49$ & 30.65 & 30.72 & & $2: 05$ & 31.22 & & \\
\hline $1: 50$ & 30.68 & 30.74 & & $2: 06$ & 31.27 & $\ldots$ & 25.8 \\
\hline 1:51 & 30.69 & & & $2: 07$ & 31.31 & . & \\
\hline $1: 52$ & 30.705 & $\ldots$ & 26.2 & $2: 08$ & 31.37 & & \\
\hline $1: 53$ & 30.72 & en. & & $2: 17$ & 31.29 & 30.55 & \\
\hline
\end{tabular}

Cooling of calorimeters, R., $0.08 \mathrm{C}$. in nine minutes, L., $0.19 \mathrm{C}$. in twentyseven minutes. Volume of right hand 389 c.c., of left hand 358 c.c.

J. S., a young laborer, was admitted to the City Hospital, March 18, suffering from tetanus. On March 9 his right thumb was injured by a machine. On March 16 pain and stiffness were present in the jaw. Three days later his back 
was stiff and painful; attacks of cramp-like rigidity occurred. When admitted there was a spastic condition of legs, arms and hands, and some spasm of the jaw. He was treated with large doses of antitoxin. The blood flow in the hands was examined on April 5. The thumb had nearly healed. The kneejerks were still exaggerated.

The hands were in bath at 1:28 p. m., in calorimeters at 1:38. At 1:50 p. m. the left hand was immersed in water at $43.5 \mathrm{C}$. At 2:00 p. m. the left hand was put into water at $7 \mathrm{C}$. At 2:08 p. m. the right hand was taken out of the calorimeter. Pulse 92, rather weak. Mouth temperature $37.3 \mathrm{C}$.

The initial flow in the hands of J. S. was subnormal for his age and the room temperature ( 5.32 grams per 100 c.c. per minute for the right hand and 6.3 grams for the left, with room temperature $25.9 \mathrm{C}$.). On immersion of the left hand in warm water the flow in the right fell to 3.32 grams per 100 c.c. per minute for the first four minutes and then rose to 9.09 grams for the remaining six minutes of the immersion. When the left hand was now put into cold water the flow in the right was cut down to 3.9 grams per 100 c.c. per minute for the first three minutes and then increased (for the remaining five minutes) to 10.14 grams per 100 c.c. per minute. The vasomotor reaction to cold accordingly, although initially intense, was not especially persistent, giving way to a marked vasodilatation while the contralateral hand was still in the cold water.

The effect of certain poisons on the vasomotor reflexes, as investigated by this method, seemed sufficiently definite to be worthy of mention.

table 27.-Calorimetric Measurements in Case of Mrs. X.

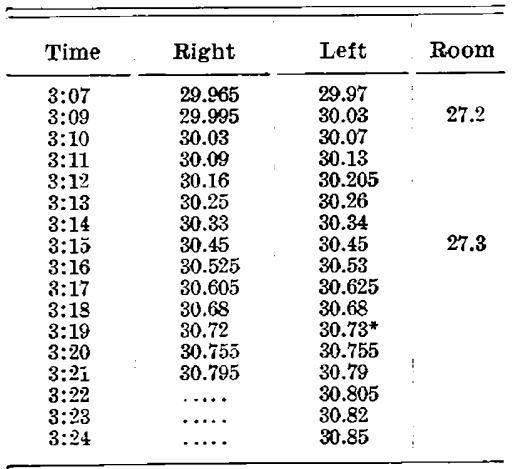

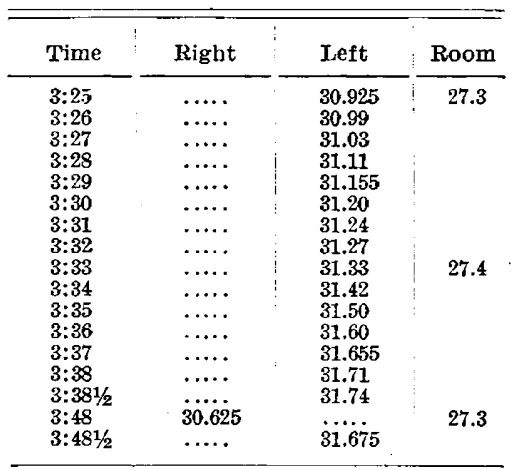

* Here she began to get nervous about the cold water which she saw in preparation being cooled by ice.

Cooling of calorimeters, R., $0.17 \mathrm{C}$. in twenty-seven minutes, L., $0.065 \mathrm{C}$. in ten minutes. Volume of right hand 317 c.c., of left hand 326 c.c.

Mrs. X., aged 48, height 4 feet, 10 inches, weight 118 pounds, was admitted at the dispensary May 11, 1911, complaining of a cough that she had had for a week. Her general health was undisturbed. She had had no children but 
eight miscarriages. She was obviously under the infuence of alcohol, and for this reason the blood flow in the hands was examined.

The hands were in bath at 2:59 p. m., in calorimeters at 3:08. At 3:21 the right hand was put into water at $8.4 \mathrm{C}$. At $3: 30$ the right hand was put into water at $43 \mathrm{C}$. At $3: 38 \mathrm{r} / 2$ the left hand was taken out of the calorimeter. Mouth temperature 37.35 C. Pulse 96.

The initial flow in this case was good ( 13.05 grams per 100 c.c. per minute for the right hand and 12.03 grams for the left), even for the relatively high room temperature $(27.3 \mathrm{C}$.). The flow in the left hand was diminished to 4.6 grams when the right was immersed in cold water. After three minutes the vasoconstriction gave place to vasodilatation, the flow increasing to 11.08 grams for the remaining six minutes of immersion of the right hand in cold water. On immersing the right hand in warm water the flow in the left sank to 7.52 grams per 100 c.c. per minute (for three minutes) and then increased to 15.92 grams per 100 c.c. per minute for the remaining five and one-half minutes of immersion, an exceptionally large increase on the top of the good initial flow. The suggestion is that the influence of the alcohol favors reflex vasodilatation of the cutaneous vessels. Evidence of this has also been secured in other cases.

In a case of lead poisoning with no symptoms of peripheral neuritis (John K.) the opposite result was obtained, good crossed vasoconstriction but practically no increase of the initial flow. In other words, the vasomotor mechanism, which under the influence of alcohol was exceptionally ready to respond to appropriate stimuli by vasodilatation, tended, under the influence of lead poisoning, to respond especially to stimuli causing vasoconstriction. In accordance with this the blood pressure was high in John $\mathrm{K}$. (180 mm. $\mathrm{Hg})$. There was no decided anemia and the flow in the hands before the vasomotor reactions were tested was within the normal range ( 8.96 grams per 100 c.c. per minute for the right hand and 8.81 grams for the left, with room temperature $23 \mathrm{C}$.).

John K., a laborer, aged 52, was admitted to the City Hospital, May 13. He worked in an automobile factory scraping paint from wheels. For two weeks he had been constipated, with intense pain in the abdomen and the occurrence of vomiting. A lead line was noted on the gums. The lips were red. A blood count showed erythrocytes $4,080,000$, leukocytes 6,800 . Knee-jerks were present and equal. The grip of the hands was not noticeably weakened. The pupils reacted to light and accommodation. The radial pulse was regular and of high tension. There was some fibrosis of the artery. He was discharged improved on May 25. The blood flow in the hands was examined May 14. He works best with his left hand though he eats and writes with the right.

The hands were in bath at $1: 43 \mathrm{p}$. m., in calorimeters at 1:55 $1 / 2$. At 2:09 the left hand was put into water at $8 \mathrm{C}$. At $2: 20$ the left hand was put into water at 43.2 C. At $2: 33$ the right hand was taken out of the calorimeter. 
TaBle 28.-Calorimetric Measurements in Case of John $\mathrm{K}$.

\begin{tabular}{|c|c|c|c|}
\hline Time & Right & Left & Room \\
\hline $1: 5 \overline{5}$ & 31.00 & 30.87 & \\
\hline $1: 57$ & 31.07 & 30.94 & \\
\hline $1: 58$ & 31.12 & 31.00 & \\
\hline $2: 00$ & 31.21 & 31.08 & \\
\hline $2: 01$ & 31.27 & 31.15 & \\
\hline $2: 02$ & 31.33 & 31.21 & 23.2 \\
\hline $2: 03$ & 31.39 & 31.27 & \\
\hline $2: 04$ & 31.45 & 31.33 & \\
\hline $2: 05$ & 31.50 & 31.39 & \\
\hline $2: 06$ & 31.56 & 31.44 & 23.0 \\
\hline $2: 07$ & 31.62 & $31.50^{*}$ & \\
\hline $2: 08$ & 31.65 & 31.53 & \\
\hline $2: 09$ & 31.68 & 31.56 & \\
\hline $2: 10$ & 31.71 & & \\
\hline $2: 11$ & 31.72 & & \\
\hline $2: 12$ & 31.735 & & \\
\hline $2: 13$ & 31.78 & $\ldots$ & 22.4 \\
\hline $2: 14$ & 31.81 & & \\
\hline $2: 15$ & 31.87 & & \\
\hline
\end{tabular}

\begin{tabular}{|c|c|c|c|}
\hline Time & Right & Left & Room \\
\hline $2: 16$ & 31.895 & & \\
\hline $2: 17$ & 31.925 & $\ldots \ldots$ & 22.3 \\
\hline $2: 18$ & 31.97 & & \\
\hline $2: 19$ & 31.99 & & \\
\hline $2: 20$ & $32.0^{2}$ & & \\
\hline $2: 91$ & 32,05 & & \\
\hline $2: 22$ & 32.075 & $\ldots$ & 22.3 \\
\hline $2: 23$ & 32.10 & encos & \\
\hline $2: 24$ & 32.125 & & \\
\hline $2: 25$ & 32.16 & & \\
\hline $2: 26$ & 32.21 & & \\
\hline $2: 27$ & 32.25 & $\ldots$ & 22.3 \\
\hline $2: 28$ & 32.295 & & \\
\hline $2: 29$ & 32.32 & & \\
\hline $2: 30$ & 32.36 & & \\
\hline $2: 31$ & 32.395 & $\ldots$ & 22.3 \\
\hline $2: 32$ & 32.435 & & \\
\hline $2: 33$ & 32.48 & & 22,4 \\
\hline $2: 46$ & 32.29 & 31.10 & \\
\hline
\end{tabular}

* Here he saw ice brought and put into the cold water and seemed to become apprehensive.

Cooling of calorimeters, R., $0.19 \mathrm{C}$. in thirteen minutes; L., $0.46 \mathrm{C}$. in thirtyseven minutes. Volume of right hand 475 c.c., of left 472 c.c. Water equivalent of calorimeters with contents, R., 3,475, L., 3,473. Puise 108.

In another case of lead poisoning (S.), a man aged 40, the flow was 8.05 grams in the right and 8.74 grams in the left hand with room temperature $21.8 \mathrm{C}$. In this case also the tendency to reflex vasoconstriction was decided, as will be seen by referring to the general table of results.

TABLE 29.-Calorimetric Measurements in Case of S.

\begin{tabular}{|c|c|c|c|c|c|c|c|}
\hline Time & Right & Left & Room & Time & Right & Left & Room \\
\hline $3: 40$ & 30.03 & 30.73 & & $3: 58$ & 31.11 & & \\
\hline $3: 41$ & 30.10 & 30.20 & 21.9 & $3: 59$ & 31.12 & & \\
\hline $3: 42$ & 30.16 & 30.26 & & $4: 00$ & 31.15 & & \\
\hline $3: 43$ & 30.20 & 30.32 & & $4: 01$ & 31.17 & & \\
\hline $3: 44$ & 30.28 & 30.39 & & $4: 02$ & 31.18 & $\ldots \ldots$ & 21.7 \\
\hline $3: 45$ & 30.335 & 30.45 & 21.8 & $4: 03$ & 31.195 & & \\
\hline $3: 46$ & 30.40 & 30.53 & & $4: 04$ & 31.26 & & \\
\hline $3: 47$ & 30.495 & 30.625 & & $4: 05$ & 31.31 & & \\
\hline $3: 48$ & 30.58 & 30.71 & & $4: 06$ & 31.375 & $\ldots$ & 22.9 \\
\hline $3: 49$ & 30.63 & 30.79 & & $4: 07$ & 31.42 & & \\
\hline $3: 50$ & 30.66 & & & $4: 08$ & 31.47 & & \\
\hline $3: 51$ & 30.69 & & & $4: 10$ & 31.53 & & \\
\hline $3: 52$ & 30.72 & & & $4: 11$ & 31.57 & & \\
\hline $3: 53$ & 30.78 & $\ldots$ & 21.9 & $4: 12$ & 31.60 & $\ldots$ & 22,8 \\
\hline $3: 54$ & 30.86 & & & $4: 13$ & 31.64 & & \\
\hline $3: 55$ & 30.91 & & & $4: 14$ & 31.695 & & \\
\hline $3: 50$ & 31.00 & & & $4: 27$ & 31.53 & 30.37 & 22.5 \\
\hline $3: 57$ & 31.07 & .... & 21.5 & & & & \\
\hline
\end{tabular}

Cooling of calorimeters, R., $0.165 \mathrm{C}$. in thirteen minutes, L., $0.42 \mathrm{C}$. in thirtyeight minutes. Volume of right hand 527 c.c., of left hand 521 c.c. Rectal temperature $38.05 \mathrm{C}$.

S., a painter, aged 40 , height 5 feet, $8 \mathrm{~T} / 2$ inches, was admitted to the City Hospital, March 31. He complained of colic, and a blue line was noted around his gums. He had been ill two or three months, and although weak was considerably better. He had no wrist-drop. He was discharged improved April 15. The blood flow in the hands was examined on April 3. Hands were in bath at $3: 29 \mathrm{p}$. m., in calorimeters at $3: 39$. At $3: 49$ the left hand was put in water 
at $8 \mathrm{C}$. He felt it very cold. At 4:01 p. m. the left hand was put into water at $43 \mathrm{C}$. At 4:09 left hand dried and wrapped. At 4:14 the right hand was taken out of calorimeter. Pulse 120 .

In Roderick D., a blacksmith, aged 27 , excessively addicted to cigaret smoking from boyhood, the flow in the hands was large (12.77 grams for the right and 12.38 grams for the left hand per 100 c.c. per minute, with the rather high room temperature of $26.2 \mathrm{C}$.). Immersion of the left hand in cold water caused a transient vasoconstriction of the right, the flow falling to 7.73 grams for the first two minutes of immersion. to rise aggain to 11.03 grams per 100 c.c. per minute for the remaining nine minutes, during which the left hand continued in the cold water. Warm water caused only a small preliminary vasoconstriction, the flow then increasing again though not quite to the high initial value. Scratching the skin with a blunt point caused a wellmarked red line which persisted for a considerable time. In this case everything points to the existence of a tendency to vasodilatation, which is in agreement with the observation that nicotin after a preliminary excitation causes depression of the sympathetic nerve cells.

Examination of flow in hands of Roderick D.: Hands in bath at $2: 35 \mathrm{r} / 2$ p. m., in calorimeters at $2: 47 \mathrm{~J} / 4$. At $2: 59$ the left hand was put into water at $8 \mathrm{C}$. He felt it very cold. At $3: 101 \% \mathrm{p} . \mathrm{m}$. the left hand was put into water at $43.5 \mathrm{C}$. At 3:21 right hand was taken out of calorimeter.

TABLE 30.-Calorimetric Measurements in Case of Roderick D.

\begin{tabular}{|c|c|c|c|}
\hline Time & Right & Left & Room \\
\hline $2: 461 / 2$ & 29.88 & 29.84 & \\
\hline $2: 48$ & 29.96 & 29.91 & \\
\hline $2: 49$ & 30.07 & 30.04 & 26.2 \\
\hline $2: 50$ & 30.19 & 30.20 & \\
\hline $2: 51$ & 30.30 & 30.31 & \\
\hline $2: 52$ & 30.435 & $30: 44$ & 26.15 \\
\hline $2: 53$ & 30.565 & 30.54 & \\
\hline $2: 54$ & 30.65 & 30.61 & \\
\hline $2: 55$ & 30.78 & 30.72 & 26.2 \\
\hline $2: 56$ & 30.87 & 30.81 & \\
\hline $2: 57$ & 31.01 & 30.90 & \\
\hline $2: 58$ & 31.09 & 30.98 & 26.3 \\
\hline $2: 59$ & 31.19 & 31.065 & \\
\hline $3: 00$ & 31.24 & & \\
\hline $3: 01$ & 31.30 & & \\
\hline $3: 02$ & 31.37 & & \\
\hline $3: 03$ & 31.46 & & \\
\hline $3: 04$ & 31.56 & $\ldots$ & 26.4 \\
\hline $3: 05$ & 31.63 & & \\
\hline
\end{tabular}

\begin{tabular}{|c|c|c|c|}
\hline Time & Right & Left & Room \\
\hline $3: 06$ & 31.70 & \multirow{11}{*}{$\ldots$} & \multirow{12}{*}{26.3} \\
\hline $3: 07$ & 31.76 & & \\
\hline $3: 08$ & 31.83 & & \\
\hline $3: 09$ & 31.90 & & \\
\hline $3: 10$ & 31.99 & & \\
\hline $3: 11$ & 32.06 & & \\
\hline $3: 12$ & 32.11 & & \\
\hline $3: 13$ & 32.17 & & \\
\hline $3: 14$ & 32.20 & & \\
\hline $3: 15$ & 32.27 & & \\
\hline $3: 16$ & 32.33 & & \\
\hline $3: 17$ & 32.39 & \multirow{3}{*}{$\ldots}$. & \\
\hline $3: 18$ & 32.46 & & \multirow{2}{*}{26.4} \\
\hline $3: 19$ & 32.52 & & \\
\hline $3: 20$ & 32.56 & \multirow{4}{*}{$\ddot{30.89}$} & \\
\hline $3: 21$ & 32.63 & & 26.5 \\
\hline $3: 22$ & ..... & & \\
\hline $3: 34$ & 32.50 & & \\
\hline
\end{tabular}

Cooling of calorimeters, R., $0.13 \mathrm{C}$. in thirteen minutes, L., $0.175 \mathrm{C}$. in twentythree minutes. Volume of right hand 535 c.c., of left hand 513 c.c. Water equivalent of calorimeters with contents, R., 3,523, L., 3,505. Mouth temperature 37.4. Pulse 84 .

The last case to be cited is that of a young man who shot himself through the brain.

Andrew K., a young foreign laborer, was brought to the City Hospital by the police on May 16, at 4:45 p. m., with a crescent-shaped wound in the scalp on the left side not far from the median line, midway between the glabella and 


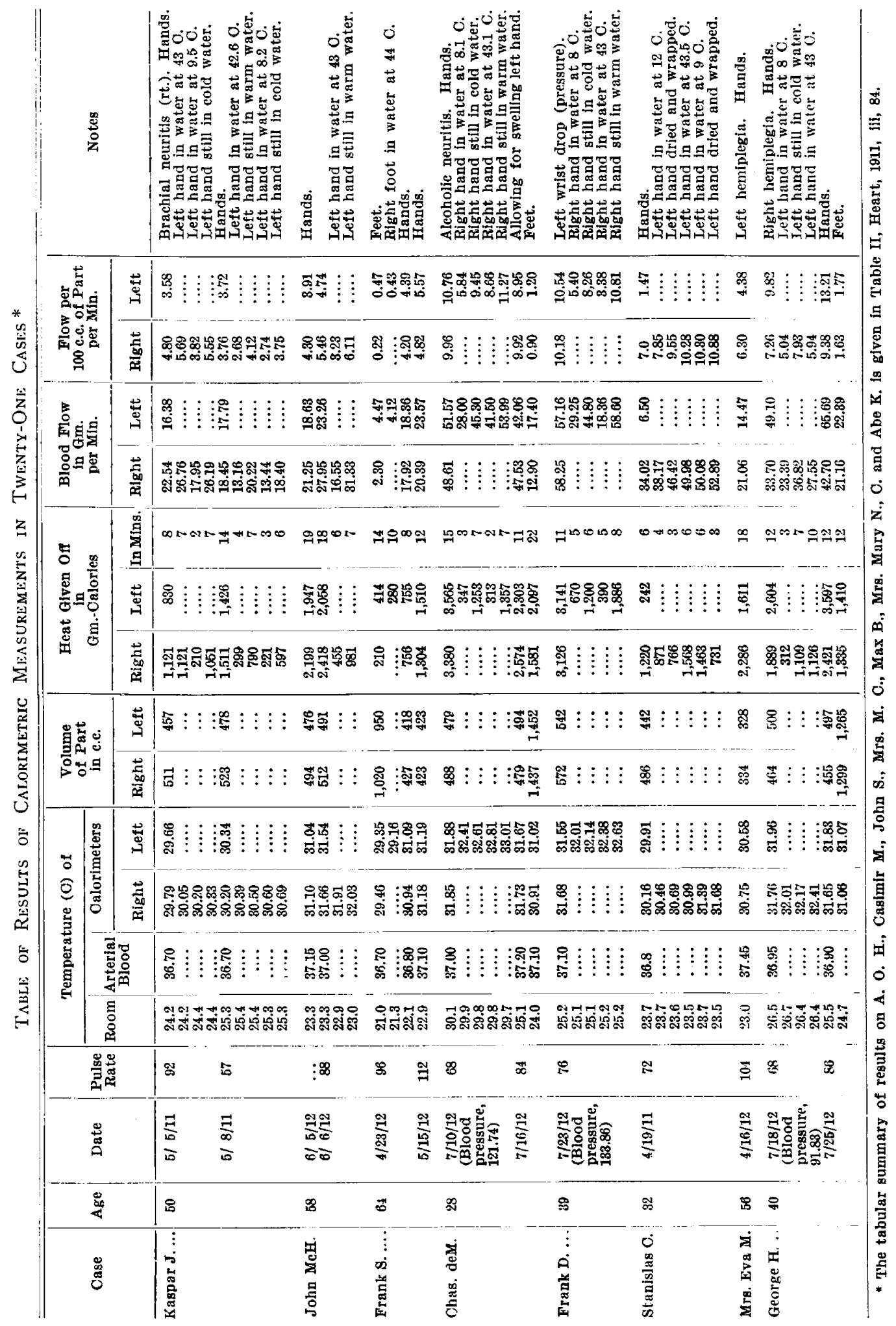




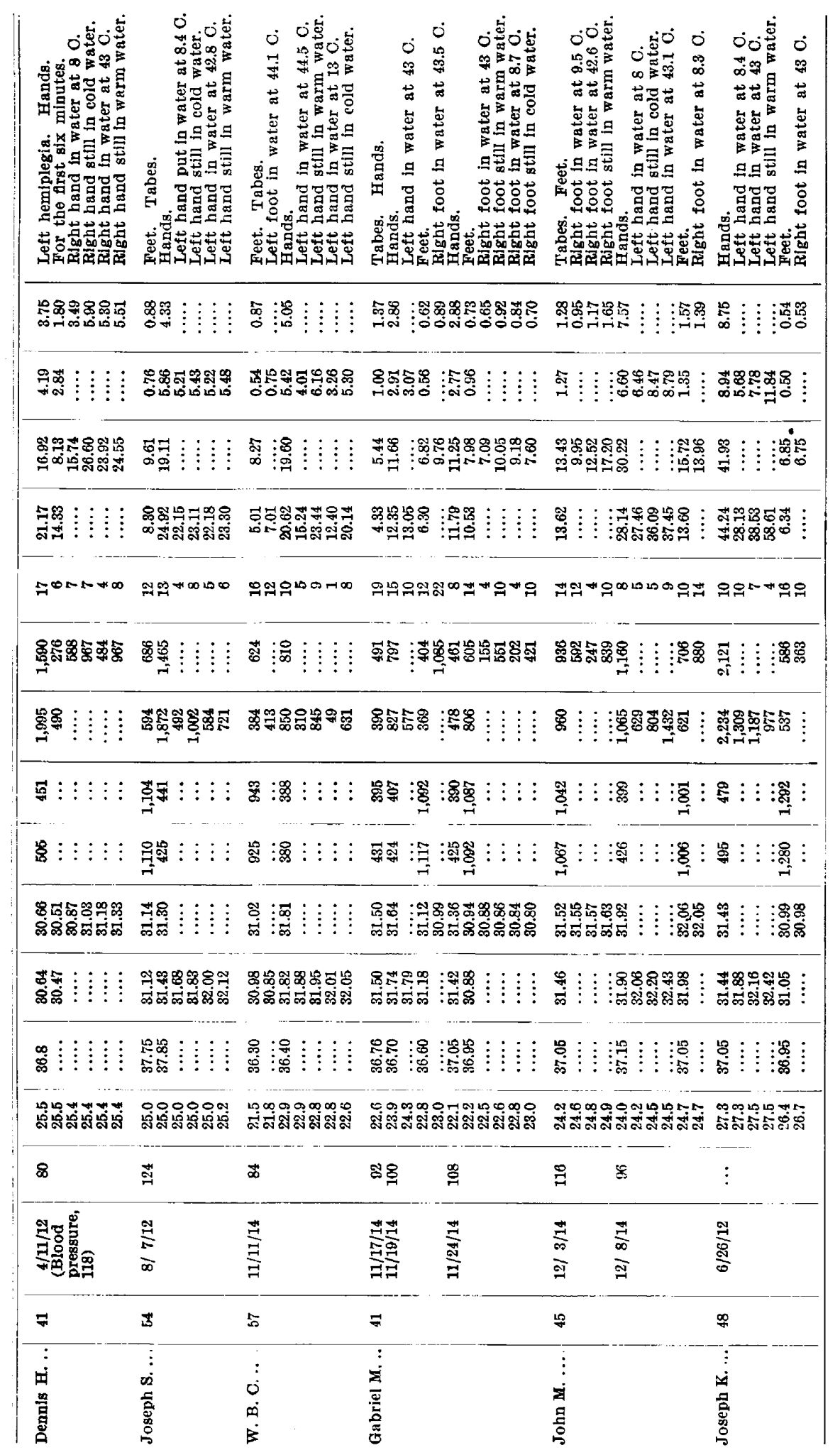




\begin{tabular}{|c|c|c|c|c|c|c|c|c|}
\hline \multicolumn{2}{|c|}{ 常 } & 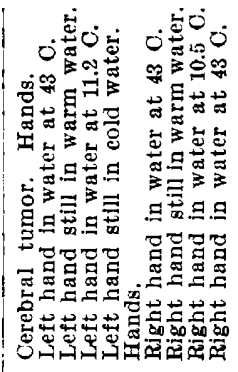 & 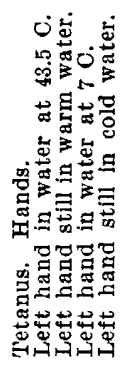 & 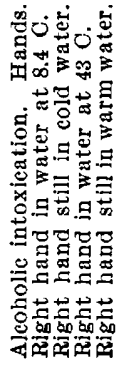 & 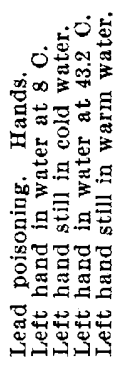 & 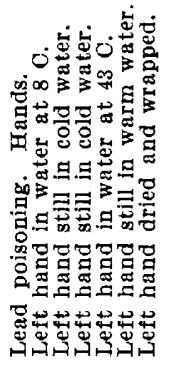 & 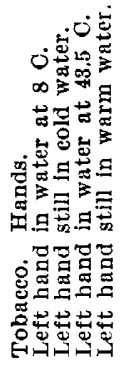 & 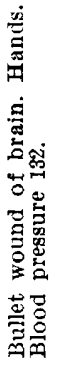 \\
\hline \multirow{2}{*}{ 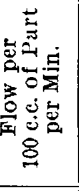 } & 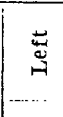 & 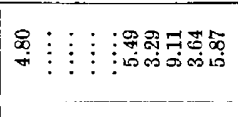 & $\begin{array}{r}\stackrel{8}{8} \vdots \vdots \vdots \vdots \\
\vdots \\
\vdots \\
-.\end{array}$ & 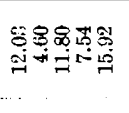 & $\begin{array}{c}\infty \\
\infty \\
\infty\end{array}$ & $\begin{array}{l}i=1 \\
\infty\end{array}$ & 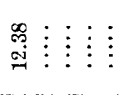 & 趈我 \\
\hline & 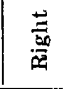 & 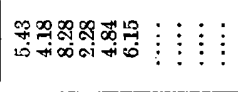 & 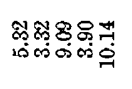 & 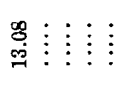 & 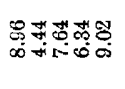 & 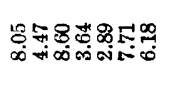 & 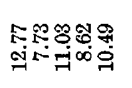 & 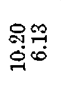 \\
\hline \multirow{2}{*}{ 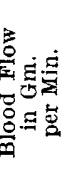 } & $\stackrel{\rightleftarrows}{\leftrightarrows}$ & 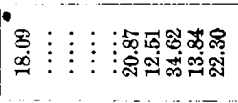 & 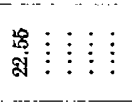 & 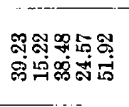 & & 荤 & 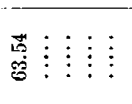 & 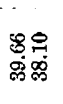 \\
\hline & 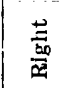 & 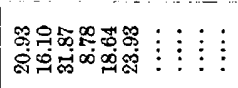 & 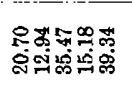 & 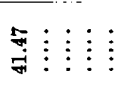 & 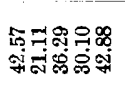 & 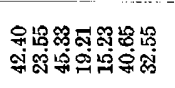 & 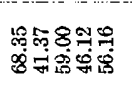 & 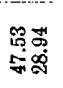 \\
\hline \multirow{3}{*}{ 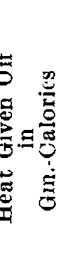 } & 离 & 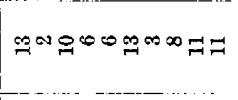 & 0000000 & Onom & $\approx \infty \infty+\infty$ & Don & चNOA & $F \Omega$ \\
\hline & $\stackrel{\vec{g}}{\leftrightarrows}$ & 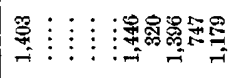 & 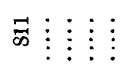 & 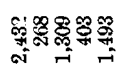 & & & 禺: & 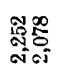 \\
\hline & $\frac{5}{\mathrm{k}}$ & 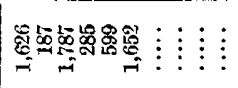 & 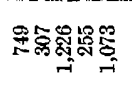 & 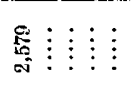 & 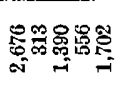 & 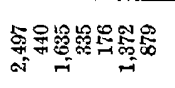 & 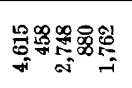 & 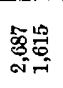 \\
\hline \multirow{2}{*}{ 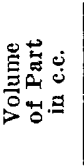 } & $\stackrel{\vec{\leftrightarrows}}{\leftrightarrows}$ & :呂 $\vdots \vdots \vdots \vdots$ & 漹 $\vdots \vdots \vdots \vdots \vdots$ & 禺 $\vdots \vdots \vdots \vdots$ & 策 & 茼 $\vdots \vdots \vdots \vdots \vdots \vdots$ & $\stackrel{\circ}{\circ} \vdots \vdots \vdots \vdots$ & 98 \\
\hline & 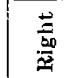 & 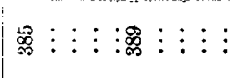 & $\mathscr{8}: \vdots \vdots \vdots$ & 水 $\vdots \vdots \vdots \vdots$ & 量 & 氮 $\vdots \vdots \vdots \vdots \vdots \vdots$ & 品 $\vdots \vdots \vdots$ & \&웎 \\
\hline \multirow{3}{*}{ 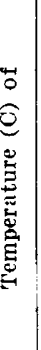 } & 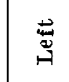 & 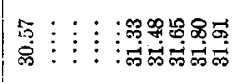 & 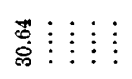 & 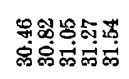 & 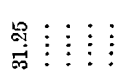 & 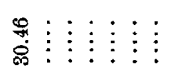 & 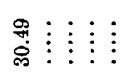 & 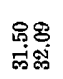 \\
\hline & 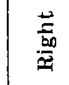 & 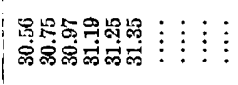 & 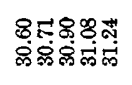 & 范 $\vdots \vdots \vdots \vdots \vdots \vdots$ & 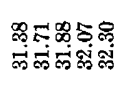 & 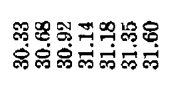 & 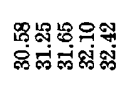 & 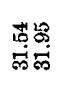 \\
\hline & 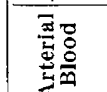 & 瓷 & 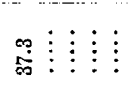 & 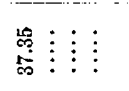 & 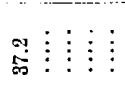 & $\stackrel{\circ}{\stackrel{\circ}{0}}$ & 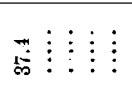 & 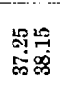 \\
\hline \multicolumn{2}{|c|}{ हू } & 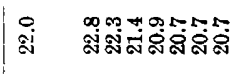 & 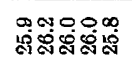 & 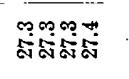 & 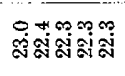 & 舟 & 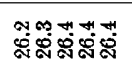 & ฌू: \\
\hline \multicolumn{2}{|c|}{ 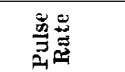 } & $\infty$ & 心 & $\&$ & $\stackrel{\infty}{9}$ & $\stackrel{乛}{్}$ & $\ddot{\infty}$ & $\not \cong$ \\
\hline \multicolumn{2}{|c|}{$\underset{\Xi}{\Xi}$} & 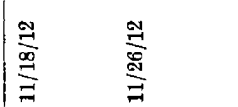 & $\frac{2}{10}$ & $\underset{20}{F}$ & 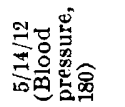 & $\frac{\text { Tे }}{\text { के }}$ & $\frac{E}{5}$ & 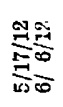 \\
\hline \multicolumn{2}{|c|}{ 苋 } & 2 & $:$ & $\mathscr{q}$ & $\hat{i}$ & क & 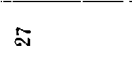 & : \\
\hline \multicolumn{2}{|c|}{ 产 } & 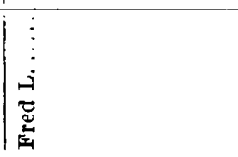 & $\begin{array}{c}\vdots \\
\vdots \\
\dot{\infty} \\
\dot{0}\end{array}$ & 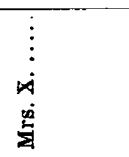 & 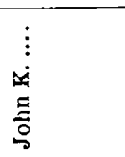 & $\begin{array}{c}\vdots \\
\vdots \\
\vdots\end{array}$ & 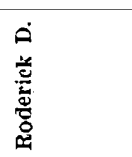 & 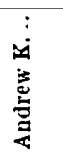 \\
\hline
\end{tabular}


occipital protuberance. The patient appeared to be in stupor; he did not talk. The right pupil was larger than the left and its outline was irregular. The pupils reacted to light. The external rectus of the right eye was paralyzed. Blood was flowing from the nostrils, but no abrasions were visible in the interior. The tongue protruded in the median line. On the hard palate was a blackish discoloration covering a bullet hole. (It was elicited afterwards that he had shot himself with a revolver.) There was no paralysis; the reflexes were normal. The rectal temperature was $98.8 \mathrm{~F}$. The spinal fluid from the lumbar puncture was bright red, containing much blood. It flowed 120 drops per minute. May 17 the eye grounds were normal. The systolic blood pressure was 140 . He voided urine involuntarily. He did not speak, although he was perfectly conscious. There was no Babinski sign. The temperature was $99.8 \mathrm{~F}$. at 8 a. m., and the same at noon. On May 18 he voided urine; the systolic blood pressure was 120 . From May 19 to May 21 his condition was the same. On May 24 the systolic pressure was 126, on June 6, 132 .

The blood flow in the hands was examined on May 17 and again on June 6 . At the first examination he sat quite well in the chair, but was absolutely silent. Hands in bath at $3: 05 \mathrm{p} . \mathrm{m}$., in calorimeters at $3: 14 \mathrm{I} / 2$, out of calorimeters at $3: 28$. Pulse 80 (lying down). Room temperature 23.4 C. He kept clutching the stirring feathers occasionally.

Table 31.-Calorimetric Measurements in Case of Andrew $\mathrm{K}$.

\begin{tabular}{|c|c|c|c|}
\hline Time & Right & Left & Room \\
\hline $3: 14$ & 31.17 & 31.17 & \\
\hline $3: 17$ & 31.22 & 31.23 & \\
\hline $3: 18$ & 31.28 & 31.26 & \\
\hline $3: 19$ & 31.33 & 31.33 & \\
\hline $3: 20$ & 31.39 & 31.36 & \\
\hline $3: 21$ & 31.45 & 31.43 & \\
\hline $3: 22$ & 31.55 & 31.52 & \\
\hline
\end{tabular}

\begin{tabular}{lll:l}
\hline \hline Time & Right & Left & Room \\
\hline $3: 23$ & 31.61 & 31.52 & \\
$3: 24$ & 31.64 & 31.59 & \\
$3: 25$ & 31.70 & 31.63 & \\
$3: 26$ & 31.77 & 31.70 & \\
$3: 27$ & 31.81 & 31.72 & \\
$3: 28$ & 31.87 & 31.76 & \\
$3: 43$ & 31.69 & 31.59 & \\
\hline
\end{tabular}

Cooling of calorimeters in fifteen minutes, R., 0.18 C., L., 0.17 C. Volume of right hand 466 c.c., of left 463 c.c. Water equivalent of calorimeters with contents, R., 3,468, L., 3,465. Rectal temperature 37.75 C.

Second examination of Andrew K., June 6: So far he has recovered without symptoms. The right pupil reacts to light equally with the left and now there is little difference in size. The right external rectus is still paralyzed. He will now talk freely. Rectal tmperature $38.65 \mathrm{C}$. Pulse (sitting) 112. Pulse not large. Hands in bath at $1: 44$ p. $\mathrm{m}$.

Table 32.-Calorimetric Measurements in Second Examination of ANDREW $\mathrm{K}$.

\begin{tabular}{c|c|c|c}
\hline Time & Right & Left & Room \\
\hline $1: 54$ & 31.68 & 31.67 & \\
$1: 56$ & 31.66 & 31.67 & \\
$1: 57$ & 31.68 & 31.70 & 22.8 \\
$1: 58$ & 31.70 & 31.74 & \\
$1: 59$ & 31.72 & 31.77 & 22.8 \\
$2: 00$ & 31.74 & 31.825 & \\
$2: 01$ & 31.78 & 31.86 & \\
$2: 02$ & 31.81 & 31.92 & \\
$2: 03$ & 31.865 & 31.97 & 22.85 \\
$2: 04$ & 31.895 & 32.025 & \\
\hline
\end{tabular}

\begin{tabular}{l|l|l|l}
\hline Time & Right & Left & Room \\
\hline $2: 05$ & 31.93 & 32.07 & 23.0 \\
$2: 06$ & 31.965 & 32.12 & \\
$2: 07$ & 31.99 & 32.155 & \\
$2: 08$ & 32.02 & 32.19 & 23.1 \\
$2: 09$ & 32.05 & 32.23 & \\
$2: 10$ & 32.08 & 32.27 & 23.0 \\
$2: 11$ & 32.11 & 32.325 & \\
$2: 19$ & 32.00 & & \\
$2: 191 / 2$ & $\cdots \cdots$ & 32.205 & \\
& & & \\
\hline
\end{tabular}

Cooling of calorimeters, R., $0.11 \mathrm{C}$. in eight minutes, L., $0.12 \mathrm{C}$. in $8^{\mathrm{T} / 2} \mathrm{~min}-$ utes. Volume of right hand in calorimeter 472 c.c., of left 460 c.c. Water equivalent of calorimeters with contents, R., 3,473, L., 3,463. 
The patient was discharged cured. He was readmitted July 31 suffering from theumatism and chronic alcoholism and was discharged "improved" on August 27.

At the first examination of Andrew K., made not much more than twenty-four hours after he was brought into the hospital, the blood flow in the right hand was 10.20 grams per 100 c.c. per minute and in the left 8.56 grams, with room temperature $23.5 \mathrm{C}$. At the second examination, nearly three weeks later, the flows were 6.13 grams and 8.28 grams respectively for the right and left hands, with room temperature $23 \mathrm{C}$. He had some fever at the time of the second examination which is perhaps associated with the somewhat smaller flows. ${ }^{11}$ It will be noted that on both occasions a distinct difference existed in the rate of flow in the two hands. The fact that there is no constancy in this difference, the greater flow being in the right hand at the first examination, in the left hand at the second, indicates that the differences are of vasomotor origin, but it is impossible to say whether they are related in any way to the brain injury. Our observations on chronic alcoholism, for which in the sequel this man was again admitted to the hospital, would perhaps suggest this rather than the brain lesion as the condition associated with the vasomotor instability. There is, of course, no obvious reason why a bullet wound through a cerebral hemisphere which occasioned no paralysis should cause a permanent difference of flow between the hands, nor indeed any obvious reason why so long as it was not associated with general symptoms it should produce any effect whatever on the circulation in the extremities. As a matter of fact, the average hand flows at the two examinations are quite within the normal range.

\section{SUMMARY}

1. In early unilateral brachial neuritis the blood flow in the affected hand was found to be decidedly greater than in the normal hand. This is interpreted as due to partial paralysis of the vasoconstrictor fibers in the nerves involved in the pathologic process.

In long-standing unilateral neuritis with decided atrophy of the affected part, the blood flow is less on the side of the lesion than on the normal side. There is some evidence that one factor in the diminution of the flow may be a change in the walls of the arteries consequent on the injury to the vasomotor nerves, which leads to diminution of the lumen. This may be considered an adaptive change correlated with the diminished function of the part. The diminution in the flow may also be due to the regaining of vascular tone by the paralyzed part, even in the absence of regeneration of its nerve supply.

11. Jour. Exper Med., 1913, xviii, 372. 
In peripheral neuritis affecting mainly muscular nerves, the changes in the blood flow of the hands and feet are not so conspicuous, as when the cutaneous nerves are also involved, since a large portion of the total flow in these parts must belong to the skin.

2. In hemiplegia there is, in general, a marked deficiency in the blood flow in the paralyzed members. Considerable differences, however, exist in different cases in this regard, and also in the extent to which the vasomotor reflexes from the normal to the paralyzed part are affected. Whether these differences depend at all on the position of the lesion or are associated with the duration and completeness of the paralysis has not been determined. There is some evidence that reflex vasoconstriction is more easily produced in the paralyzed parts than reflex vasodilatation.

3. In tabes, the blood flow in both hands and feet, but especially in the feet, has been found decidedly subnormal and the vasomotor reflexes feeble.

4. In lead poisoning (without paralysis), the tendency to reflex vasoconstriction was conspicuous. This seemed to be the case also in alcoholic neuritis. In alcoholic intoxication and in a case of excessive cigaret smoking, the opposite was observed, namely, a tendency to marked reflex vasodilatation.

5. It is suggested that, in some cases, examination of the blood flow might aid in the detection of malingering, when the attempt is made to simulate certain neuropathologic conditions. It seems probable that the differential diagnosis, for instance, between such conditions as cerebral hemorrhage and alcoholic intoxication, or between hysterical palsy and paralysis due to an organic lesion, in doubtful cases might be facilitated by blood-flow measurements.

I wish to express my obligations to the staffs of the City Hospital and of Lakeside Hospital for aid without which this investigation could not have been carried out. 